Federal Reserve Bank of Minneapolis

Research Department Staff Report 235

August 1997

\title{
Marital Risk and Capital Accumulation
}

\author{
Luis Cubeddu* \\ International Monetary Fund \\ José-Víctor Ríos-Rull* \\ Federal Reserve Bank of Minneapolis \\ and University of Pennsylvania
}

\begin{abstract}
Between the sixties and the late eighties the percentages of low-saving single-parent households and people living alone have grown dramatically at the expense of high-saving married households, while the household saving rate has declined equally dramatically. A preliminary analysis of population composition and savings by household type seems to indicate that about half of the decline in savings is due to demographic change. We construct a model with agents changing marital status, but where the saving behavior of the households can adjust to the properties of the demographic process. We find that the demographic changes that reduce the number of married households (mainly higher divorce and higher illegitimacy) induce all household types to save more and that the effect on the aggregate saving rate is minuscule. We conclude that the drop in savings since the sixties is not due to changes in household composition.

*We thank Albert Ando, Juan Pablo Córdoba, Hal Cole, Gary Hansen, Tim Kehoe, Lee Ohanian, Edward Prescott, and numerous seminar participants for helpful comments. We also thank Juan Pablo Córdoba and Vincenzo Quadrini for help with data analysis. Cubeddu thanks the Boettner Institute for financial support; Ríos-Rull thanks the National Science Foundation for Grant SBR-9309514. The views expressed herein are those of the authors and not necessarily those of the Federal Reserve Bank of Minneapolis, the Federal Reserve System, or the International Monetary Fund.
\end{abstract}




\section{Introduction}

Since the sixties, U.S. households have experienced a dramatic change in their structure and composition. Between 1960 and 1990, the percentage of single-parent households increased from $3.4 \%$ to $12.0 \%$, while the percentage of traditional family households dropped from $81.9 \%$ to $59.7 \%$ over the same period. Changes in the patterns of household formation and dissolution have, to a large extent, been responsible for the described transformation of U.S. households. Since the sixties, the rate of divorce has more than doubled, while the incidence of childbearing outside of marriage has increased fourfold. ${ }^{1}$ In addition, the average household rate of saving out of disposable income has fallen dramatically, from $8.95 \%$ for the periods $1960-61$ and $1972-73$ to $4.17 \%$ for the period $1984-90 .^{2}$ In this paper we study whether changes in the structure of households, product of changes in divorce and illegitimacy patterns, have influenced, in a quantitatively significant manner, the behavior of aggregate saving.

To understand how changes in the patterns of household formation and dissolution affect the aggregate saving of a society, we start by describing an expression that aggregates the saving of households. Let a society be composed of a certain number of household types, identical within each type. Household types are denoted by $j=\{1, \cdots, J\}=\mathcal{J}$, and the number of each type by $\mu_{j}$, with $\sum_{j \in \mathcal{J}} \mu_{j}=1$. Let $s_{j}$ correspond to the savings of type $j$, $y_{i}$ the income of type $j$, and $\hat{s}_{j}=\frac{s_{j}}{y_{j}}$ the saving rate of type $j$. The aggregate saving rate of a society, $\hat{S}$, is given by the ratio of a weighted average of group-specific saving rates and aggregate income, $\hat{S}=\sum_{j \in \mathcal{J}} \mu_{j}\left(\frac{y_{j}}{Y}\right) \hat{s}_{j}$, where $Y$ denotes aggregate income. The expression allows us to decompose changes in the overall saving rate into changes in the relative size $\mu_{j}$, relative income $\frac{y_{j}}{Y}$, and saving behavior $\hat{s}_{j}$ of each group.

Since changes in the patterns of household formation and dissolution imply changes in the population structure, we might expect an increase in the overall saving rate should the share of traditionally low saving types decrease. To evaluate the direct impact on saving of changes in the structure of households, we compute the aggregate saving rate that results from

\footnotetext{
${ }^{1}$ Other factors responsible for changes in the structure of U.S. households include, most noticeably, changes in the age structure of the population, the postponement of marriage, the rise in cohabitation, and the delay and reduction in childbearing.

${ }^{2}$ The fall in the household saving rate can also be shown with other measures. See Section 2.
} 
assuming the behavior and income distribution of the eighties, yet the population structure of the sixties. This means computing $\sum_{j \in \mathcal{J}} \mu_{j}^{60}\left(\frac{y_{j}}{Y}\right)^{80} \hat{s}_{j}^{80}$, where the superscript denotes the period the variable refers to. This calculation yields a saving rate that is $55 \%$ higher than the actual saving rate in the eighties. At first glance, the result would seem to imply that over half of the decline in the rate of saving has been the result of changes in the population structure.

However, this exercise makes sense only if both the relative income and the saving behavior of households have not been affected by the observed changes in population structure. In other words, changes in the patterns of household formation and dissolution affect the aggregate saving rate not only through their direct effect on the relative size of household types, but also through indirect means by affecting the relative income and saving behavior of households. These indirect effects could change our assessment, perhaps dramatically, regarding the role of demographics in shaping aggregate saving.

Of all the social changes that have worked to reduce the relative size of married households (increased divorce, increased out-of-wedlock births, reduced mortality, postponement of marriage, delayed and reduced childbearing, and increased cohabitation), perhaps the two most important and, hence, most responsible for recent changes in the demographic structure are the falls in mortality and fertility rates that have produced an aging population and the increases in divorce and out-of-wedlock birth rates that have reduced the percentage of married couples in the population. The impact of population aging on savings has been studied extensively in the literature. Auerbach, Kotlikoff, Hagemann, and Nicoletti (1989) and Auerbach and Kotlikoff (1992) employ a dynamic general equilibrium life cycle model to evaluate the effect of population aging on the U.S. rate of capital accumulation. They find that the changes in the U.S. population since the sixties, all else equal, cannot explain the observed decline in the aggregate saving rate. Ríos-Rull (1994) also finds that in the early stages of the population aging in Spain, the saving rate should increase, not decrease. More recently, Gokhale, Kotlikoff, and Sabelhaus (1996) have used a national accounts-based, life-cycle framework to understand the drop in the U.S. saving rate. They find that had the age distribution of the population in the sixties prevailed in the eighties, the U.S. saving 
rate would have been lower, rather than higher. ${ }^{3}$ Gokhale, Kotlikoff, and Sabelhaus (1996) attribute part of the decline in saving since the early sixties to the growth in government transfer programs (Social Security, Medicare, and Medicaid) and to increases in the marginal propensity to consume of the elderly). In this paper, we explore the effect on aggregate saving of the other key demographic phenomenon, the increase in the percentage of single and single-parent households, the product of increases in the rates of divorce and illegitimacy.

Changes in the likelihood of divorce and illegitimacy, what we term marital risk, imply changes in the incentive to save of households. People are generally made worse off after divorce or an out-of-wedlock birth. Economies of scale in household size, increasing returns in market and home production activities, and the transaction costs involved in splitting the couple into two different households render divorce an undesirable event for the parties involved. An out-of-wedlock birth will not only increase a household's consumption needs, but also reduce a woman's current and future financial well-being (the latter by reducing her likelihood of marriage). Since households cannot insure themselves against these singleparenthood risks, a greater likelihood of divorce and illegitimacy may induce a desire to save more because of standard precautionary motives. ${ }^{4}$ However, an increase in the incidence of divorce may work to discourage saving. Divorce procedures involve legal and real estate fees that reduce the net worth and consequently the return to saving of the divorced couple. In addition, divorce, when associated with remarriage, will reduce incentives to save. Divorce involves the splitting of assets between ex-partners, and remarriage involves the sharing of the already reduced assets with the new partner. ${ }^{5}$ It is difficult to get a sense of the relative strengths of these opposing effects ex-ante.

In answering our question, we pose a general equilibrium overlapping generations model. We distinguish between the sexes and assume agents are subject to exogenous unin-

\footnotetext{
${ }^{3}$ While the age distribution of the sixties had relatively more middle-aged individuals than the age distribution of the eighties, it also had relatively fewer younger individuals.

${ }^{4}$ Empirical evidence suggests that single-parenthood risks are associated with important income losses. Johnson and Skinner (1986) find a dramatic reduction of a female's family income net of her labor earnings within two years after divorce. Bane and Ellwood (1986) find that $11 \%$ of all poverty spells are triggered by transition into female-headed families, either through divorce $(64 \%)$ or an out-of-wedlock birth.

${ }^{5}$ According to Cherlin (1992), over $75 \%$ of all divorced people remarry, and the median length of time between divorce and remarriage is about three years.
} 
surable changes in the type of household that they form that resemble U.S. patterns. ${ }^{6}$ A married couple solves a joint maximization problem where the interest of each spouse is considered. We assume a couple to be a unit with community property and equalization of consumption across both members. Each period, households decide how much to save and consume, yet we abstract from explicitly modeling time allocation and fertility decisions.

We calibrate a baseline model to the economic and demographic characteristics of the eighties and conduct the same type of analysis on the model as we have on the data. Consistent with the results obtained from the data, in our model when we fix the relative income and saving behavior of households, yet use the population structure associated with the divorce and illegitimacy patterns of the sixties, we obtain a much higher saving rate.

To properly account for the indirect effects of demographic change on saving, we compute the equilibria of an economy that differs from the baseline model economy in that the patterns of divorce and illegitimacy are consistent with those found in the sixties. Contrary to the naive assessment that changes in the structure of households can account for over half of the decline in the rate of saving, we find that the saving rate in this model economy is only $2 \%$ higher than that found in the baseline model. The explanation lies in that while a larger fraction of high-saving households exist, households save less when faced with a lower incidence of divorce and illegitimacy. We find that increases in marital risk work to encourage, rather than to discourage, saving, as the precautionary motive to save dominates the implicit lower return to saving associated with higher divorce risk.

When we isolate the demographic change into changes due to illegitimacy only and changes due to divorce only, we find that each factor contributes in the same proportion to changes in the household's saving behavior. We also study the role of changes in earnings between the sixties and the eighties by posing a model economy that differs from the baseline not only in the divorce and illegitimacy patterns, but also in the relative earnings distribution, so that changes reflect the patterns of the sixties. In this context, our model predicts that the combination of increased marital risk and changes in earnings will increase rather than

\footnotetext{
${ }^{6}$ As far as we know, the only two-sex model constructed is by Kotlikoff and Spivak (1981), who are only interested in studying how the family could provide insurance against uncertain longevity to its members, yet abstract from many other features of marriage.
} 
decrease saving. We find that our results are robust to a variety of other versions of the model economies, which differ on the most delicate features of our calibration: the size of the pecuniary costs associated with divorce and the relative weight assigned to each member of the couple.

Finally, we study whether some reduction in saving can be associated with the fact that people have been pre-empting these social changes. It could very well be that households during the sixties behaved according to the rules of divorce and illegitimacy of the eighties. For the hypothesis to hold true, household saving would have had to increase sharply before the sixties and decrease monotonically thereafter. However, the empirical evidence suggests that no such important increase in saving rates occurred in the United States between the fifties and the sixties.

We proceed as follows. Section 2 analyzes U.S. data on household saving in an attempt to isolate each of the three factors (population structure, relative income distribution, and saving behavior) that might have contributed to the decline of the aggregate saving rate. Section 3 describes the model and defines the equilibrium. Section 4 describes the calibration procedures for the baseline model economy, while Section 5 describes the model's properties. Section 6 describes the behavior of the model economies calibrated like the baseline except for some features that were prevalent in the sixties: namely, lower divorce rates, lower illegitimacy rates, and a different earnings distribution. Section 7 explores the robustness of our findings across several dimensions. In Section 8, there is an analysis of the plausible properties of a transition from a low divorce and illegitimacy regime to one where marital risk is greater. Section 9 concludes and suggests extensions for further research. Appendix 1 describes the computational algorithm. Appendix 2 provides certain details of the calibration procedures. Appendix 3 includes relevant tables and figures.

\section{Data Analysis on Aggregate Saving Rates}

In this section, we use U.S. data to study changes in the aggregate saving rate by decomposing these changes into changes in population structure, relative income distribution, and saving behavior. The data are from Córdoba (1996), which uses the Consumption Expenditure Survey (CEX). Since this survey started being collected continuously in 1979, 
for the sixties, we use the averages of the surveys 1960-61 and 1972-73. Data for the eighties refer to the period 1984-1990. For each household in the survey, a measure of income and a measure of consumption are constructed. The notion of income used was that of disposable personal income. This notion excludes pension plan contributions both voluntary and compulsory, is net of taxes, and includes transfers both from the public sector and from private pension plans. Some adjustments are made to include the services of owner-occupied housing (which, of course, are also included in the notion of consumption). To compute saving for each household, a comprehensible measure of consumption was subtracted from that of income. $^{7}$

This is not exactly the notion of household saving that we use in our model, since we abstract from the public sector and treat contributions to pension plans as saving and cash receipts from them as dissaving, but it serves the purposes of studying the role of household structures. Note that other measures of saving rates, such as the net national saving rate, fell from $9.1 \%$ to $4.7 \%$ between the sixties and eighties and follow a very similar pattern. ${ }^{8}$

The population is partitioned into three groups: people living alone, single parents, and households with multiple members. ${ }^{9}$ For each household type $j$, we obtain measures of the household's relative size $\mu_{j}$, its average income relative to total income $\frac{y_{j}}{Y}$, and its average saving rate $\hat{s}_{j}$. As we noted in the introduction, the saving rate in year $t, \hat{S}^{t}$, is given by the expression

$$
\hat{S}^{t}=\sum_{j \in \mathcal{J}} \mu_{j}^{t}\left(\frac{y_{j}^{t}}{Y^{t}}\right) \hat{s}_{j}^{t}
$$

where $Y^{t}$ is total disposable income. Recall that aggregate household saving as a proportion of disposable income equals $8.95 \%$ in the sixties and $4.17 \%$ in the eighties.

A way of analyzing the contribution of each of these three factors - changes in population structure $\left(\mu_{j}\right)$, changes in relative incomes $\left(\frac{y_{j}}{Y}\right)$, and changes in behavior $\left(\hat{s}_{j}\right)$-is to compute the saving rate that one would obtain mixing factors of the eighties and the six-

\footnotetext{
${ }^{7}$ See Córdoba (1996) for details on how a variety of data issues, such as top-coding, are dealt with.

${ }^{8}$ Table A5 in Appendix 3 borrows from Gokhale, Kotlikoff, and Sabelhaus (1996) the evolution of net national saving rates by decade going back to the fifties. Net national savings is defined as the net national product net of consumption and government expenditures.

${ }^{9}$ There is a slight difference in the way we partition dependents. In the model dependents are considered single heads of household without dependents, but not in the analysis by Córdoba (1996). This feature accounts for some of the differences in the household structure between the model and data.
} 
ties. For example, the saving rate that would be obtained with the population structure of the sixties but with the relative incomes and saving behavior of the eighties is given by the expression $\sum_{j \in \mathcal{J}} \mu_{j}^{60}\left(\frac{y_{j}}{Y}\right)^{80} \hat{s}_{j}^{80}$.

Table 1 shows the hypothetical saving rates for different combinations of population structure, relative incomes, and saving behavior. The results should be interpreted as what would have been the saving rate in the eighties under the assumption that one or two of the three factors were of the sixties. The first row of Table 1 normalizes the actual saving rate of the eighties in the United States to unity, while the last row shows the normalized saving rate for the sixties. The key properties of the data are as follows:

Table 1: United States: Actual and Hypothetical Saving Rates of the Eighties

\begin{tabular}{llll}
\hline & & Expression & Saving Rate \\
\hline Actual Saving Rate of the Eighties & & $\sum_{j \in \mathcal{J}} \mu_{j}^{80}\left(\frac{y_{j}}{Y}\right)^{80}{ }_{\hat{s}_{j}^{80}}$ & 1.00 \\
Population Structure of the Sixties & $\sum_{j \in \mathcal{J}} \mu_{j}^{60}\left(\frac{y_{j}}{Y}\right)^{80}{ }_{\hat{s}_{j}^{80}}$ & 1.55 \\
Relative Incomes of the Sixties & $\sum_{j \in \mathcal{J}} \mu_{j}^{80}\left(\frac{y_{j}}{Y}\right)^{60}{ }_{\hat{s}_{j}^{80}}$ & 0.87 \\
Population Structure and Incomes of the Sixties & $\sum_{j \in \mathcal{J}} \mu_{j}^{60}\left(\frac{y_{j}}{Y}\right)^{60}{ }_{\hat{s}_{j}^{80}}$ & 1.38 \\
Actual Saving Rate of the Sixties & $\sum_{j \in \mathcal{J}} \mu_{j}^{60}\left(\frac{y_{j}}{Y}\right)^{60}{ }_{\hat{s}_{j}^{60}}$ & 2.15 \\
\hline
\end{tabular}

1. If population had been that of the sixties, while relative income distribution and behavior were that of the eighties, then the saving rate would have been about $55 \%$ higher than the actual eighties values. This is because the percentage of high-saving married households was much higher in the sixties than in the eighties.

2. If we assume the eighties population structure and saving behavior, yet the relative income distribution of the sixties, then we would observe a saving rate lower than the actual eighties value. The explanation lies in that the relative incomes of all groups actually increased between the sixties and the eighties in roughly the same proportion for all household types.

3. If saving behavior is that of the eighties, while the population structure and relative incomes are that of the sixties, then savings would be about $38 \%$ percent higher than 
the actual eighties value. The result indicates that the effect of population structure on aggregate saving is more important than the effect of relative incomes.

4. Finally, the sixties saving rate, which, of course, is the product of the sixties population structure, relative incomes, and saving behavior, was more than double the rate found in the eighties. The result is consistent with the argument that households behaved less thriftily in the eighties than in the sixties.

To summarize, there was a dramatic reduction in the U.S. saving rate between the sixties and the eighties, with the former being more than twice that of the latter. Of this overall reduction, changes in both the population structure and the saving behavior appear to have contributed to the decline in the saving rate, while changes in the relative incomes appear to have had the opposite effect. In terms of the size of these effects, it seems that the quantitatively more important of the three is the actual change in the saving behavior of households, while the least important is the change in the relative incomes of households. Nevertheless, changes in population structure (recall that with this term we refer only to the partition of households into people living alone, single parents, and households with multiple adult members) seems to account, by itself, for about half of the decline in the personal saving rate observed in the United States between the sixties and the eighties.

\section{The Model}

The model is a growth model with overlapping generations, where agents differ in sex and marital status. Agents of different sex see their marital status altered exogenously through marriage, divorce, widowhood, and the acquisition of dependents.

\section{A Demographics}

The economy is inhabited by agents who live a maximum of $I$ periods but face a mortality risk. We denote their age by $i \in \mathcal{I}=\{1, \cdots, I\}$. Agents also differ in sex, denoted $g \in\{m, f\}$, where $m$ and $f$ refer to male and female, respectively. These characteristics evolve over time in the obvious way: next-period agents who survive are one period older and have the same sex as today. Survival probabilities depend only on age and sex. The probability of surviving between age $i$ and age $i+1$ for an agent of sex $g$ is denoted $\gamma_{i, g}$, and the unconditional 
probability of being alive at age $i, \gamma_{g}^{i}$, is, therefore, $\gamma_{g}^{i}=\prod_{j=1}^{i-1} \gamma_{j, g}$. Agents are also indexed by their marital status, $z \in Z$. The types of marital status that we consider are single without dependents $s_{o}$, single with dependents $s_{w}$, and married. Distinguishing married agents by the age of their spouse is a necessity for internal consistency. The outlook that agents face depends on the age of the spouse, since future earnings and consumption requirements are affected by it. The set of possible marital types is then given by $Z=\left\{s_{o}, s_{w}, 1, \cdots, j, \cdots, I\right\}$. We assume that the process for marital status is exogenous with age- and sex-specific transition probabilities denoted $\pi_{i, g}\left(z^{\prime} \mid z\right)$. To avoid excessive notation, we define transition matrices $\pi_{i, g}$, so that their rows add up to $\gamma_{i, g}$. Population grows at an exogenous rate $\lambda_{\mu}$. Agents' demographic characteristics are then given by the triad $\{i, g, z\}$. We use $\mu_{i, g, z}$ to denote the measure of agents of type $\{i, g, z\}$.

A stable population is one that has constant ratios over time across the different demographic groups. ${ }^{10}$ This implies that the measure of the different types satisfies the following relation:

$$
\mu_{i+1, g, z^{\prime}}=\sum_{z} \frac{\pi_{i, g}\left(z^{\prime} \mid z\right)}{\left(1+\lambda_{\mu}\right)} \mu_{i, g, z}
$$

where we are using the standard convention in recursive analysis of denoting next period's variables with primes.

Note that a key property of this model economy is that the measure of age $i$ males married to age $j$ females must equal the measure of females age $j$ married to males age $i$ :

$$
\mu_{i, m, j}=\mu_{j, f, i} \quad \text { for all } \quad i, j \in \mathcal{I}
$$

\section{B Preferences and Endowments}

We assume agents to be completely selfish in the sense that they do not care for others, neither spouses nor dependents. Instead, we restrict their consumption to be the same as that of their spouses and/or dependents.

Agents do not care about leisure, and they value effective streams of consumption in a standard way. ${ }^{11}$ Household type affects how consumption expenditures transform into en-

\footnotetext{
${ }^{10}$ This concept can be thought of as the demographic counterpart of a steady state.

${ }^{11}$ We abstract from explicitly modeling time allocation and fertility decisions of households. See Becker
} 
joyable consumption flows, which takes into account both the local externality that arises in the married living arrangement and the fact that different types of households have different sizes. For a single household without dependents, consumption is enjoyed one-for-one. This is not the case for single households with dependents, where one unit of consumption expenditure translates into $\frac{1}{\eta_{i, g, s w}}$ units of effective consumption. Within a couple, both spouses are restricted to consume the same amount of the good. A couple's consumption expenditure translates into $\frac{1}{\eta_{i, g, j}}$ units of consumption for each spouse. ${ }^{12}$ We can write all this in a compact way as a state-dependent per period utility function:

$$
u_{i, g, z}(c)=u\left(\frac{c}{\eta_{i, g, z}}\right)
$$

Agents discount the future at rate $\beta$ and only care if they survive. The lifetime expected utility of an agent of type $\{i, g, z\}$ at birth is

$$
E\left\{\sum_{i=1}^{I} \beta^{i-1} \gamma_{i, g} u_{i, g, z}(c)\right\}=\sum_{i=1}^{I} \beta^{i-1} \sum_{z^{\prime}} \pi_{i-1, g}\left(z^{\prime} \mid z\right) u_{i, g, z}(c)
$$

where $\pi_{0, g}\left(z^{\prime} \mid z\right)$ is the probability distribution of marital types for newborns.

Agents are endowed with one unit of time per period, which they supply inelastically. One unit of time of a type $\{i, g, z\}$ agent is transformed into $\varepsilon_{i, g, z}$ units of labor input.

\section{Markets}

We look only at situations where prices are constant over time, that is, steady states. There are spot markets for labor and for capital with the price of an efficiency unit of labor denoted $w$ and with the rate of return of capital denoted $r$. In addition, to avoid the cumbersome issue of dealing with the assets of the deceased, we allow for annuities markets for single households and allow them jointly for married households (only contingent upon the death of both spouses). We do not allow for life insurance markets (contingent upon the death of one of the married partners, life insurance pays the survivor), nor do we allow for the

(1991) for a complete survey on these issues.

${ }^{12}$ Distinguishing the coefficient $\eta_{i, g, j}$ by household type enables us to account for differences in the number of dependents found in each type of household without having to extend household types to include family size. 
existence of insurance for marital risk. That is, households cannot insure against marriage, divorce, or the acquisition or loss of dependents. The lack of life insurance markets is chosen for simplicity, and we do not believe this is an important quantitative issue for the question at hand. The absence of insurance markets for changes in household type is based on obvious moral-hazard considerations. We also impose a nonborrowing constraint, although this can be easily relaxed by noting that with this market structure, the obligation to repay in every state of the world generates a maximum level of indebtedness. Agents with different marital histories will have different accumulated assets $a \in \mathcal{A}$, where $\mathcal{A}$ is the set of possible asset holdings. Given that we consider only situations where factor prices are constant and where agents have finite lives, there will be an upper bound on the assets held by any agent. This makes the set $\mathcal{A}$ a compact set.

\section{The Single Agent's Problem}

We write the problem of the single agent in recursive form by using value functions. We denote by $v_{i, g, z}(a)$ the residual expected utility of a type $\{i, g, z\}$ agent with assets $a$. The problem of single agent $z \in\left\{s_{w}, s_{o}\right\}$ can be written as

$$
\begin{array}{rlrl}
v_{i, g, z}(a) & =\max _{c \geq 0, y \in \mathcal{A}} u_{i, g, z}(c)+\beta \gamma_{i, g} E\left\{v_{i+1, g, z^{\prime}}\left(a^{\prime}\right) \mid z\right\} & \text { s.t. } \\
c+y & =(1+r) a+w \varepsilon_{i, g, z} & & \text { if } z^{\prime} \in\left\{s_{o}, s_{w}\right\} \\
a^{\prime} & =\frac{y}{\gamma_{i, g}} & & \text { if } z^{\prime} \in\{1, \cdots, I\} .
\end{array}
$$

When an agent becomes married, the assets of the couple will equal the sum of the assets of

both spouses. We denote by $A_{z^{\prime}, g^{*}}$ the assets that the spouse age $z^{\prime}$ and sex $g^{*}$ brings into the marriage, where $g^{*}$ generically denotes the opposite sex to that of the individual agent that we are considering. These assets are a random variable, since the set of prospective spouses, even within each age group, have different wealth levels. Therefore, in assessing their future expected utility and, hence, in determining how much to save, agents must know the asset distribution of their potential spouses. 


\section{E The Married Couple's Problem}

The married couple is a household unit where agents are constrained to enjoy equal amounts of the consumption good. Moreover, we assume that they are subject to a common property regime. This means that no distinction can be made based on the assets brought to the marriage by each of the spouses, and, hence, the household will not be indexed by prenuptial variables. Since on average females live longer than males, are younger than their spouse, and earn less than males (particularly if they are likely to become single with dependents in the near future), females are more likely to wish to save more.

The problem of the household is to determine how much to consume and save. However, there is no unique solution to determine how such a decision is reached. ${ }^{13}$ Our approach is to solve a weighted joint maximization problem, which at least guarantees that the outcome is efficient. ${ }^{14}$ We define the weight assigned to an $\{i, g, z\}$ agent as $\xi_{i, g, z}$. Normalization of the sum of the weights to one implies that $\xi_{i, g, j}=1-\xi_{j, g^{*}, i}$ for all $i, j \in \mathcal{I}$.

Should the marriage end in divorce, common assets are divided between the spouses. We define as $\psi_{i, g, j}$ the fraction of assets that goes to an individual of type $\{i, g, j\}$ upon separation the next period. This variable is designed to incorporate the present value of alimony and child support dependent on financial assets. In addition, since divorce is associated with legal and real estate costs, this function may also determine the degree to which assets are destroyed in the divorce procedures, allowing for the possibility that $\psi_{i, g, j}+\psi_{j, g^{*}, i}<1$.

With all of the above considerations, we can write the decision problem of a married couple as

$$
\begin{array}{ll}
\max _{c \geq 0, y \in \mathcal{A}} & u_{i, g, j}(c)+\beta \gamma_{i, g} \xi_{i, g, j} E\left\{v_{i+1, g, z_{g}^{\prime}}\left(a_{g}^{\prime}\right) \mid j\right\}+\beta \gamma_{j, g^{*}} \xi_{j, g^{*}, i} E\left\{v_{j+1, g^{*}, z_{g^{*}}^{\prime}}\left(a_{g^{*}}^{\prime}\right) \mid i\right\} \\
\text { s.t. } & c-y=(1+r) a+w\left(\varepsilon_{i, g, j}+\varepsilon_{j, g^{*}, i}\right)
\end{array}
$$

\footnotetext{
${ }^{13}$ Browning (1994) models the saving decision in a two-person household, where selfish members control their own income. In his setup, the intrahousehold resource allocation is determined by differences in earnings between the married partners. Browning, Bourguignon, Chiappori, and Lechene (1994) show that earnings differences between married partners have a small but statistically significant effect over the couple's consumption distribution.

${ }^{14}$ An added difficulty in posing the decision-making problem of the couple is the fact that it is a repeated situation, as more often than not, the spouses face the saving decision more than once.
} 
where

- if there is no divorce

$$
a_{g}^{\prime}=a_{g^{*}}^{\prime}=\frac{y}{\gamma_{i, g}+\gamma_{j, g^{*}}-\gamma_{i, g} \gamma_{j, g^{*}}}
$$

- if there is divorce and no remarriage

$$
\begin{aligned}
& a_{g}^{\prime}=\frac{\psi_{i, g, j}}{\gamma_{i, g}+\gamma_{j, g^{*}}-\gamma_{i, g} \gamma_{j, g^{*}}} y \\
& a_{g^{*}}^{\prime}=\frac{\psi_{j, g^{*}, i}}{\gamma_{i, g}+\gamma_{j, g^{*}}-\gamma_{i, g} \gamma_{j, g^{*}}} y
\end{aligned}
$$

- if there is divorce and remarriage

$$
\begin{aligned}
& a_{g}^{\prime}=\frac{\psi_{i, g, j}}{\gamma_{i, g}+\gamma_{j, g^{*}}-\gamma_{i, g} \gamma_{j, g^{*}}} y+A_{z_{g}^{\prime}, g^{*}} \\
& a_{g^{*}}^{\prime}=\frac{\psi_{j, g^{*}, i}}{\gamma_{i, g}+\gamma_{j, g^{*}}-\gamma_{i, g} \gamma_{j, g^{*}}} y+A_{z_{g^{*}, g}} .
\end{aligned}
$$

Since married partners share equal consumption, there is no need to be explicit about the utility weights in the current period. Note that the expectation takes into account all possible changes in marital status, including divorce and remarriage with another person of the same demographic characteristics as the former spouse. The denominator in equations (11) - (16) is the term associated to the annuities markets that applies for the case of death of both partners. [See Ríos-Rull (1996) for details.]

\section{F Equilibrium}

Definition 1 A stationary equilibrium is a pair of factor prices $\{w, r\}$, a set of decision rules for consumption $c_{i, g, z}(a)$ and saving $y_{i, g, z}(a)$, a collection of random variables that denote asset holdings formation $a_{i, g, z}^{\prime}(a)$, and probability measures $\phi_{i, g, z}$ for all $\{i, g, z\}$ such that

1. Given factor prices, agents' decision rules solve the maximization problem.

2. The relation between the saving decision $y_{i, g, z}(a)$ and next-period asset holdings $a_{i, g, z}^{\prime}(a)$ is consistent with the married couple's community property regime, the sharing rule 
$\psi_{i, g, z}$, and the distribution of assets across prospective spouses $\phi_{j, g^{*}, i}$ as described above.

3. Individual and aggregate behavior are consistent:

$$
\phi_{i+1, g, z^{\prime}}(B)=\sum_{z \in Z} \pi_{i, g}\left(z^{\prime} \mid z\right) \int_{a \in \mathcal{A}} \chi_{a_{i, g, z}^{\prime}(a) \in B} \quad \phi_{i, g, z}(d a)
$$

where $\chi_{a_{i, g, z}^{\prime}(a) \in B}$ denotes the indicator function that takes the value of one if the statement is true and zero otherwise.

Note that in this definition, there is no determination of factor prices, which implies that we assume that the model is of a small open economy. To extend the model to a closed economy, it suffices to add one condition to the definition that links aggregate factors of production to factor prices by assuming competition and an aggregate production function in which marginal productivities equal factor prices. We choose the simple route of the small open economy because it saves the outermost computational loop, which for the model economies studied, reduces the computational burden to a tolerable level. (See Appendix 1 for details.) The contribution of the general equilibrium effects of changes in the environment has been studied in the literature since Auerbach and Kotlikoff (1987), and is a well-known issue. [See also Ríos-Rull (1994) for a comparison between the closed and open economy implications of an aging population on saving.]

\section{Calibration of the Baseline Model Economy (the Eighties)}

We start with calibrating the demographic characteristics of our baseline model economy, associated with the demographic regime of the eighties. We then calibrate preferences, individual labor earnings, household equivalence scales (which determine the relation between consumption expenditures and consumption enjoyment by household size), the economic properties of marriage and divorce, and factor prices. The section ends with a description of changes in the calibration necessary to reproduce the demographic and earnings process of the sixties. 


\section{A Demographics}

The length of the period is five years. Agents are assumed to be born at age 15 and can live up to age 85 , after which death is certain. This implies that at any point, there are agents in 14 different age groups, and that each individual is indexed by one of 16 marital statuses: single without dependents $s_{o}$, single with dependents $s_{w}$, and married. Married agents are indexed according to the age of the spouse, who can belong to any of the 14 age cohorts. Our characterization of single without dependents includes nonmarried dependents (nonmarried cohabiting couples are thought of as married) as well as single heads of households without dependents. All single with dependents are heads of households. For expository purposes, the sets of married and single agents are defined as $M$ and $S$, respectively, so we have $Z=S \times M$.

We assume that at birth, the numbers of males and females are equal. ${ }^{15}$ The annual rate of population growth, $\lambda_{\mu}$, is assumed constant at $1.2 \%$, which approximately corresponds to the average U.S. rate over the past three decades. Age- and sex-specific survival probabilities are taken from the 1988 United States Vital Statistics Mortality Survey.

We use the Panel Study of Income Dynamics (PSID) to obtain the transition probabilities across marital statuses. We track agents over a 5-year period, between 1980 and 1985, to evaluate changes in their marital status. Since the model distinguishes married agents not only by their age, but also by the age of their spouse, we find the PSID sample size to be too small to compute directly the transition probabilities. As a result, we are forced to make certain assumptions to derive the model's transition probabilities across marital statuses. Furthermore, we also have to adjust the transition probabilities to make them compatible across the sexes so that the number of married males of age $i$ with an age $j$ wife, $\mu_{i, m, j}$, equals the number of married females of age $j$ with age $i$ husbands, $\mu_{j, f, i}$. If these transitions are estimated from the data, both the existence of measurement error and the fact that the sample population is not stationary in age distribution imply that the population structure derived from the transitions does not satisfy the above restriction, unless the transitions are adjusted.

From the PSID, we obtain the following transition probabilities across marital sta-

\footnotetext{
${ }^{15}$ Even though males slightly outnumber females at birth, by age 15 the numbers of males and females are close to identical.
} 
tuses according to age and sex: $\hat{\pi}_{i, g}\left(z \mid s_{o}\right), \hat{\pi}_{i, g}\left(z \mid s_{w}\right),\left\{\hat{\pi}_{i, g}\left(s_{o} \mid j\right)\right\}_{j \in M},\left\{\hat{\pi}_{i, g}\left(s_{w} \mid j\right)\right\}_{j \in M}$, and $\hat{\pi}_{i, g}(M \mid M)$, for $i \in \mathcal{I}, g \in\{m, f\}$, and $z \in Z$. In order to obtain a finer partition of the transition functions, we compute from the PSID data the percentage of agents who, while remaining married between 1980 and 1985, change spouses. We condition these probabilities according to age and sex, and we denote them $q_{i, g}$. In Appendix 2, we describe the set of assumptions and operations used to obtain the much finer partition of the transitions that are needed in the model economies.

Tables A1 and A2 in Appendix 3 show the transition probabilities for the baseline economy. A closer look at them allows us to highlight several important facts: females marry before males, females outlive males, upon divorce most females retain child custody, and most single parents are females. We use these transition probabilities to generate the baseline economy's stationary population distribution. We find that the distribution of individuals according to their marital type resembles that found in the United States in 1988. (See Figures 1, 2, and 3.) There are some differences between the structure of the population generated by the model and that in the data. The differences between them are due to the fact that, while in the model the population is stationary, in the data the demographic implications of changes in the patterns of household formation and dissolution (including reduced fertility and mortality rates) have yet to take their full effect.

\section{B Preferences}

We assume that utility exhibits constant relative risk aversion:

$$
U(c)=\frac{c^{1-\sigma}}{1-\sigma}
$$

where $\sigma$ is the coefficient of relative risk aversion. This is the parameter for which it is hardest to assign a value. We have chosen a value of 1.5 , since it's the most commonly used in economies without leisure. [See the discussion in Ríos-Rull (1996).] ${ }^{16}$ Since we are using the small open economy approach, the value for the discount factor, $\beta$, cannot be determined

\footnotetext{
${ }^{16}$ Precautionary saving in response to risk is associated with convexity of the marginal utility function or a positive third derivative. Our preferences guarantee a positive precautionary saving motive. See Kimball (1990) for more on this issue.
} 
as a function of the rate of return. We instead assume an annual value of 0.98 . Among those who have tried to explicitly measure it, Hurd (1989) obtains an upper bound of 1.011, while other estimates usually deliver a lower value. [Again, see the discussion in Ríos-Rull (1996).]

\section{Individual Labor Earnings}

Age-, sex-, and marital-status-specific labor earnings, $\varepsilon$, are compiled from the Current Population Survey (CPS) March demographic files for 1988. Figure 4 shows that for all ages and marital statuses, males outearn females. Labor earnings differences are greatest between married males and females, while earnings of single head of household males are only slightly greater than those of single head of household females. In addition, for most age groups, married males outearn single males, while single females without dependents outearn females who are single parents or married.

\section{Household Equivalence Scales}

To determine how expenditures in consumption translate into consumption enjoyed by each household member, we use the household equivalence scales of the Organization for Economic Cooperation and Development, where the first adult counts as 1, the second as 0.7, and each child as 0.5. [See Ringen (1991).] In this fashion, a married couple with two children has to spend $2.7 \$$ in order for each member of the household to enjoy $1 \$$ of consumption.

Obviously, for singles without dependents, the household size is one, and the required expenditures per household dollar of consumption are also one. For singles with dependents, we assume that the household equivalent size is 1.75 (which corresponds to 1 adult with 1.5 children or to 1 adult with slightly above 1 dependent adult). For married couples, we assume a concave shape that peaks at the 35-40 age group of the female spouse. Specifically, we assume that wives ages 15-19 have one dependent, that by ages 35-39 they must care for two dependents, and that by ages 55 all their children are supposed to be out of the household. The above is summarized in Table A3 in Appendix 3.

\section{E Marriage and Divorce}

When marriage ends in divorce, common assets are divided. Since divorce procedures involve important legal and real estate costs, we assume that $40 \%$ of the married couple's 
net worth is destroyed in the separation process. In addition, to account for the fact that, in general, it is the female who retains custody of the children upon divorce, we assume that females' share of the assets is much larger than that of the males. The reason for this is that summarizing the present value of child support payments reduces the enormous computational burden associated with keeping track of the marital histories of each individual agent. Specifically, we have chosen $\psi_{i, m, j}=0.2$ and $\psi_{f}=0.4$ for all $i, j \in \mathcal{I}$. Because this is a central issue in our paper, we also explore the implications of a model economy where separation costs are zero. (See Section 7.)

Finally, we assume that when solving the maximization problem, the future of each spouse is given equal consideration; that is, $\xi_{m}=\frac{1}{2}=\xi_{f}$. Here again, we study the implications of assuming different weights for each spouse. (See Section 7.)

\section{F Factor Prices}

We assume an open economy, where the internationally given net return to capital is $4 \%$ per annum. In this context, the wage, or price of one unit of efficient labor, can be normalized to unity.

\section{G The Model Economy With Low Marital Risk (the Sixties)}

Recall that in this paper, we abstract from studying the implications of changes in the age structure of the population. Therefore, from our point of view, the demographic processes of the sixties and the eighties differ only in the incidence of divorce and illegitimacy. More specifically:

1. The incidence of divorce was 2.3 times higher in the eighties than in the sixties. [DaVanzo and Rahman (1993) document that the incidence of divorce increased from 9 in 1000 married females to 21 in 1000 married females between 1960 and 1988.]

2. The incidence of illegitimacy was four times higher in the eighties than in the sixties. [Nonmarital births as a percentage of all births increased from 5\% in 1960 to $25 \%$ in 1990. See DaVanzo and Rahman (1993) for a more in-depth discussion.]

Next, we describe how to transform the demographic process of the baseline economy, represented by the $\pi$ 's, to obtain the demographic regime of the sixties. We denote the transition 
probabilities for the sixties model economy as $\pi^{l o w}$.

1. We compute the probability of divorce of a type $\{i, g, j\}$ agent, $d_{i, g}(j)$, for the baseline economy. We assume that divorce is positive as long as the probability of marital dissolution is greater than the likelihood of spousal death. In other words,

$$
d_{i, g}(j)=x_{i, g}(j)-\left(1-\gamma_{j, g^{*}}\right)
$$

Since the probability of divorce is 2.3 times less likely for all agents regardless of their age and sex, we define the probability of marital dissolution for the sixties demographic regime as

$$
x_{i, g}^{l o w}(j)=\left(1-\gamma_{j, g^{*}}\right)+\frac{d_{i, g}(j)}{2.3}
$$

We then compute transition probabilities, $\pi_{i, g}^{l o w}(z \mid j)$, with the same procedure described in equation $(A 7)$, substituting $x_{i, g}^{\text {low }}(j)$ for $x_{i, g}(j)$.

2. Next, we assume that the transition from single without dependents to single with dependents is four times less likely than in the baseline case:

$$
\pi_{i, g}^{l o w}\left(s_{o} \mid s_{o}\right)=\frac{\pi_{i, g}\left(s_{w} \mid s_{o}\right)}{4}
$$

The likelihood of becoming married increases, while the likelihood of remaining single without a dependent remains unaltered:

$$
\begin{aligned}
\pi_{i, g}^{\text {low }}\left(s_{o} \mid s_{o}\right) & =\pi_{i, g}\left(s_{o} \mid s_{o}\right) \\
\pi_{i, g}^{l o w}\left(M \mid s_{o}\right) & =1-\pi_{i, g}^{l o w}\left(s_{o} \mid s_{o}\right)+\pi_{i, g}^{l o w}\left(s_{w} \mid s_{o}\right) .
\end{aligned}
$$

In addition, we assume that the ratios between $\pi_{i, g}^{l o w}\left(j \mid s_{o}\right)$ and $\pi_{i, g}^{l o w}\left(M \mid s_{o}\right)$ equal those found in the baseline economy for all $i, j \in\{1, \cdots, I\}$.

3. Finally, we implement step 3 of the procedure specified for the baseline economy to make the transitions of males and females consistent with each other. 
With the transition probabilities of the sixties so obtained, we find that the distribution of agents according to marital status in the low marital risk economy to resemble that found in the United States in 1966. (Compare Figures 1, 5, and 6. ${ }^{17}$

We also want to explore the role of changes in the relative earnings of agents in each demographic group. These changes have been non-trivial; for instance, female earnings have grown relative to their male counterparts. Age, sex, and marital status dependent labor earnings are computed using the CPS March demographic file for 1966. Labor earnings are normalized using the same procedure described in the baseline economy. (See Figure 7.) We find that between 1966 and 1988, labor earnings, in efficiency units, have increased 54\% for married females, $12 \%$ for females without dependents, and $34 \%$ for females with dependents. The increase in the relative earnings of females can, to a large extent, be explained by the dramatic rise in the participation of females in the labor market. Between 1966 and 1988, the labor force participation rate of married females increased from $38.8 \%$ to $62.1 \%$, while that of single females have increased from $56.9 \%$ to $69.1 \%$ over the same period. Conversely, male labor market participation rates observed little change. The participation rates of married males fell from $95.6 \%$ to $89.26 \%$, while the rates of single males increased from $70.0 \%$ to $76.4 \%$ between 1966 and $1988 .{ }^{18}$

\section{Properties of the Baseline Model Economy}

In this section, we describe the main properties of the baseline model economy and compare them with those found in the U.S. data between 1984 and 1990.

The aggregate saving rate in the data is $4.16 \%$, while in our baseline model it is higher: $6.18 \%$. This should be of no surprise, since the model was not calibrated to match this statistic. To obtain the data's aggregate saving rate, our model would need either a lower discount rate or a lower rate of return. Consequently, our model is not designed to account for aggregate saving, but rather for how saving depends on the demographic structure. Given the computational burden, we chose not to target the aggregate saving rate and to concentrate

\footnotetext{
${ }^{17}$ Since we abstract from changes in the age structure of the population, the demographic regime of the sixties economy has an older population age structure than that found in the United States in the sixties.

${ }^{18}$ The fall in male labor force participation can be attributed to early retirement, perhaps induced by more generous pension benefits.
} 
on how it responds to different demographic scenarios.

Table 2 documents the composition of the population, the relative incomes, and the saving rate for married households, singles without dependents, and singles with dependents both in the data and in the baseline model economy. In what follows we compare certain features of the model with the data.

Table 2: Properties of the Baseline Model Economy and the U.S. Data

\begin{tabular}{|c|c|c|c|c|}
\hline \multicolumn{5}{|c|}{ Baseline Model Economy } \\
\hline & \multirow[t]{2}{*}{ Overall } & \multirow[t]{2}{*}{ Married } & \multicolumn{2}{|c|}{ Single } \\
\hline & & & No Dependents & Dependents \\
\hline Household Distribution in Percentages & 100 & 29.0 & 52.9 & 18.1 \\
\hline Income Relative To Single w/o & 1.77 & 3.54 & 1.00 & 1.18 \\
\hline Saving Rates Relative to Average & 1.00 & 2.48 & -1.36 & -0.29 \\
\hline \multicolumn{5}{|c|}{ U.S. Data: 1984-1990 } \\
\hline & \multirow[t]{2}{*}{ Overall } & \multirow[t]{2}{*}{ Married } & \multicolumn{2}{|c|}{ Single } \\
\hline & & & No Dependents & Dependents \\
\hline Household Distribution in Percentages & 100 & 59.7 & 28.3 & 12.0 \\
\hline Income Relative To Single w/o & 1.75 & 2.25 & 1.00 & 1.15 \\
\hline Saving Rates Relative to Average & 1.00 & 1.88 & -1.38 & -2.55 \\
\hline
\end{tabular}

We start by observing large differences in the distribution of households across types between the model and the data. These differences are due to the following:

- The way we categorize dependents differs from the way they are categorized in the data. Córdoba (1996) partitions the population into three groups: people living alone, single parents, and households with multiple members. Our model partitions households similarly, yet in contrast to Córdoba (1996), we regard dependents as heads of household. ${ }^{19}$ Consequently, our model overstates the share of single households in the economy. The reason for our modeling choice of not treating agents as dependent adults is that there is no good evidence of what happens upon separation, that is, how assets are split. We leave for future research the consideration of the more complex family structures where multiple adults coexist in the same household. Note, however, that when we treat dependents in the data as we do in our model, we find that in the data, $38.6 \%$ of

\footnotetext{
${ }^{19} \mathrm{~A}$ single dependent in the data is considered a single head of household in our model, while a married dependent in the data is considered a spouse or head of a married household.
} 
households are married, $54.9 \%$ are single without dependents, and the remaining $6.5 \%$ are single households with dependents. These results show a much closer fit between the demographic structures of the data and model.

- Differences in the composition of households also result from the fact that while population in the model is stationary, in the data it is far from being so. It takes time for the increase in divorce and illegitimacy rates to generate large numbers of single households. If the current divorce and illegitimacy rates remain in place for a while, the fraction of single households will increase in the data.

- The stationary characteristic of the model's population structure also implies that the population in the model is older than in the data. The reason lies in that the aging of the population implied by the current fertility and mortality patterns has not yet been completed in the United States.

Note also that the fact that a higher percentage of married households is found in our model than in the data is a feature that is common to the calibration of the demographics scenario of both the eighties and the sixties. Since we are interested in the relative differences between these two demographic scenarios, we think that this issue is of minor importance.

With respect to the relative incomes across household types, we see that the model exaggerates the relative incomes of the married households, while being consistent with that of the single households. The reasons are as follows:

- Relative earnings differences between the model and the data, the product of the already described demographic differences, can, to a large extent, explain the relative income differences between households. Since there exists a high percentage of low-earning young single households in our model than in the data, a consequence of differences in which single dependents are categorized, the relative earnings of married households will be exaggerated. Using CPS 1988 data, we find that earnings of married households are 2.6 times greater than the earnings of single households, while in the baseline model, this ratio is 5 . However, if we were to classify dependents in the data as we have done in the model, then the earnings of married households would be 4.3 times greater than those of single households, rather than the ratio of 2.6 that we found. 
- Relative income differences also reflect differences in capital earnings, the product of differences in the the accumulation of wealth of households. This issue is discussed below.

Regarding the relative saving rates of households, the key property, that married households save more than single households, shows up more dramatically in our model than in the data. These differences can be attributed to the following:

- Single households with dependents dissave more in the data than in the model. These households may tend to underreport the earnings of dependents. Since consumption is consolidated, this would yield a very large dissaving rate in the data.

- Married households save slightly more in the model than in the data. The lack of social security in the model may explain why the saving rate of married households is greater in the model than in data. In the data, part of the saving for retirement are made through the social security system, which does not get recorded as either saving or disposable income.

- Single households without dependents dissave roughly the same amount in the model as in the data. While there exists a higher percentage of dissaving older households in the model than in the data, there also exists a higher percentage of low-saving young single households. The effects counteract, producing, on average, a saving rate for single households that is similar in the model and in the data. ${ }^{20}$

We find there exist important differences in the characteristics of household types in the data and in the baseline model. These differences are mostly due to the fact that to properly account for the data, much more complex household and fiscal structure have to be used. We think, however, that the differences do not pertain to the central issue at stake, the role of changes in divorce and illegitimacy rates in shaping the aggregate saving rate.

Next, we study the extent to which the model fits the data's age profile for wealth, income, and consumption features. We compare our findings to those documented in a recent

\footnotetext{
${ }^{20}$ Dissaving at old age in the model will be greater than in the data simply because, as mentioned before, we have abstracted from social security.
} 
study by Quadrini and Ríos-Rull (1997), who employ the 1989 and 1992 Survey of Consumer Finances of 1992 to study the U.S. wealth, income, and earnings distributions. The average wealth-age profiles for the different types of household for the baseline model economy are shown in Figure 8, where the age of a married couple is given by the age of the female spouse. Following a similar pattern as that observed in the data, we find that average household wealth increases with age, up until age 60-64, decreasing thereafter. (Figure 9 shows the same graph for the data.)

The average saving rates of households increase with age up until age 40-44 and fall monotonically thereafter. (Households begin to dissave their wealth at age 60-64.) We find that the old-age dissaving rate is much higher for single households than for married couples. The explanation may lie in that since females outlive males, females' greater desire to save will translate into lower old-age dissaving by married couples. The above explanation might shed some light on the important question of why households do not de-accumulate wealth as quickly as standard life models might predict.

Beacuse of differences in marital status histories, agents of the same age and sex may have different wealth holdings. This feature allows us to explore the within-age-cohort heterogeneity in wealth, income, and consumption levels. In what follows, we assess the extent to which our model can explain some stylized facts about the U.S. wealth, income, and consumption inequality.

Our model is capable of generating a lot of wealth inequality. The household wealth Gini coefficient is 0.65 , while the top $20 \%$ and $5 \%$ of households own $63 \%$ and $23 \%$ of wealth, respectively. This compares to 0.78 for the Gini index and to shares of $79 \%$ and $53 \%$ of wealth for the top quintile and top $5 \%$ in the data. ${ }^{21}$ Note that in our model, only demographic variables account for wealth differences: there are no shocks to earnings besides those associated with marital status. The explicit modeling of household arrangements thus might go a long way toward accounting for the wealth inequality in the United States. [See Quadrini and Ríos-Rull (1997) for an analysis of the excessive wealth concentration in the United States.]

The within-age-cohort household wealth inequality falls monotonically with age. In the data, we observe that wealth inequality falls with age until age 40-45, yet increases thereafter.

\footnotetext{
${ }^{21}$ The source is the 1992 Survey of Consumer Finances: see Díaz-Gimenez, Quadrini, and Ríos-Rull (1997).
} 
The per adult wealth Gini coefficient is slightly lower at 0.63 , while the corresponding wealth inequality falls with age until age 65-69 and increases thereafter. The overall household income Gini coefficient is 0.35 , compared with 0.57 in the data. Household income inequality increases with age until age 15-29 and falls thereafter. In the data, income inequality follows a similar trend, yet increases once households approach retirement. As expected, the per adult income Gini coefficient is lower at 0.24 . In contrast with the per household measure age, per adult income inequality falls with age until age 40-44 and increases monotonically thereafter.

Finally, we examine the validity of the open economy assumption. If we assume a Cobb-Douglas production technology with a capital income share of 0.36 and a depreciation rate of $7 \%$ per annum, the wealth-to-labor ratio in the model economy would be larger than the capital-to-labor ratio required to guarantee a net return to capital of $4 \%$ per annum. The above implies that under these assumptions our economy is a net exporter of capital. More specifically, $14 \%$ of the total wealth of households would be held in accounts abroad.

At this point, we can proceed to compute the hypothetical saving rate of an economy with the saving behavior and relative income of the baseline model economy, but with the population structure based on the divorce and illegitimacy patterns of the sixties. When we do this exercise, we obtain a saving rate of $11.67 \%$, which implies an $83 \%$ increase over the actual saving rate of the model economy. (The same exercise in the data yields a saving rate which is $55 \%$ higher than the actual eighties value.) The result indicates that the structure of the population of the sixties is more prone to save than that of the eighties. Since singleparent households generally observe lower labor earnings per head and greater consumption expenditure per household member, their savings per head are less than those of married households. Therefore, an increase in the share of single-parent households, all else equal, translates into a reduction in the overall saving rate.

However, in order to assess the complete effect of changes in the incidence of divorce and illegitimacy, we have to study the equilibrium of an economy where agents face lower marital risk and act accordingly. We turn to such an economy in the next section. 


\section{Features of the Low Marital Risk Economy}

We construct a model economy that differs from the baseline model in that the likelihoods of divorce and illegitimacy resemble the patterns found in the United States during the sixties. This low marital risk economy will not only have a much higher share of high-saving married households, but household saving behavior will reflect the reduced incidence of marital risk. Table 3 allows us to compare certain features of the low marital risk model with those in the baseline model. ${ }^{22}$ Not only does the low marital risk model have a higher percentage of married households, but each household type also has, on average, lower relative incomes and lower saving rates than the baseline model. The resulting overall equilibrium saving rate for the low marital risk economy is $6.52 \%$, a mere $2 \%$ higher than the saving rate found in the baseline model.

Table 3: Properties of the Low Marital Risk Model

\begin{tabular}{lcccc}
\hline & Overall & Married & \multicolumn{2}{c}{ Single } \\
& & & No Dependents & Dependents \\
\hline Household Distribution & $100 \%$ & $44.3 \%$ & $46.7 \%$ & $9.0 \%$ \\
Relative Incomes & 1.00 & 1.684 & 0.435 & 0.561 \\
Saving Rates & $6.52 \%$ & $15.57 \%$ & $-19.98 \%$ & $-20.84 \%$ \\
\hline
\end{tabular}

Now that we have computed the equilibrium of the low marital risk economy, we are in a position to carry out the same analysis we performed on the data. (See Section 2.) Table 4 documents the calculations of actual and hypothetical saving rates derived from the baseline and low marital risk models. (For the sake of comparison, we also reproduce the values from Table 1 that refer to the U.S. data.) Saving rates are normalized so that the equilibrium saving rate of the baseline eighties model is unity.

1. If we assume the population structure and saving behavior of the eighties model economy, yet the relative income distribution of the low marital risk model, like in the data, we find a lower-than-actual saving rate. The explanation lies in that the relative income of all groups increased between the sixties and the eighties (despite the fact that the earnings distribution was assumed constant at the eighties baseline level).

\footnotetext{
${ }^{22}$ Table A4 in Appendix 3 shows in some detail all the possible combinations of population structure, relative incomes, and saving behavior in the baseline economy and the economies with alternative calibrations.
} 
Table 4: Model Economy: Actual and Hypothetical Saving Rates. (Demographic Change Only)

Expression Saving Rate

\begin{tabular}{|c|c|}
\hline Actual Saving Rate of the Eighties & $\sum_{j \in \mathcal{J}} \mu_{j}^{80}\left(\frac{y_{j}}{Y}\right)^{80} \hat{s}_{j}^{80}$ \\
\hline Population Structure of the Sixties & $\sum_{j \in \mathcal{J}} \mu_{j}^{60}\left(\frac{y_{j}}{Y}\right)^{80} \hat{s}_{j}^{80}$ \\
\hline Relative Incomes of the Sixties & $\sum_{j \in \mathcal{J}} \mu_{j}^{80}\left(\frac{y_{j}}{Y}\right)^{60} \hat{s}_{j}^{80}$ \\
\hline Population Structure and Incomes of the Sixties & $\sum_{j \in \mathcal{J}} \mu_{j}^{60}\left(\frac{y_{j}}{Y}\right)^{60} \hat{s}_{j}^{80}$ \\
\hline Actual Saving Rate of the Sixties & $\sum_{j \in \mathcal{J}} \mu_{j}^{60}\left(\frac{y_{j}}{Y}\right)^{60} \hat{s}_{j}^{60}$ \\
\hline
\end{tabular}

2. An economy with the saving behavior of the eighties baseline model, but the population structure and relative incomes of the sixties shows about $56 \%$ higher saving than actual (compared to $36 \%$ in the data). Like in the data, the result indicates that the effect of population structure on aggregate saving is far more important than that of relative incomes.

3. Finally, the saving rate in the low marital risk economy is only $2 \%$ higher than that of the baseline model economy. The result indicates not only that households are less prone to save when the likelihoods of divorce and illegitimacy are reduced, but also that the magnitude of the effect is large enough to offset increases in saving due to the increased presence of high-saving married households.

To summarize, we find that changes in the structure of households that have resulted from the increase in the risk of divorce and illegitimacy cannot account for the dramatic reduction in the U.S. saving rate between the sixties and the eighties, as the data suggest. In contrast to the data, our model predicts that changes in saving behavior, induced by increases in marital risk, should have worked to offset most of the increase in saving that has resulted from the increase in the percentage of high-saving households. ${ }^{23}$

\footnotetext{
${ }^{23}$ The model and the data concord on the effects of changes in population structure and relative incomes on saving.
} 


\section{A The Equilibrium Effect of Changes in Relative Earnings}

As documented in Section 6, the relative earnings of households have undergone profound changes since the sixties. In this section, we study the role that changes in the relative earnings of households have played in shaping aggregate saving. For that, we construct a model that differs from the baseline in that both its marital risk and relative earnings distribution match the patterns found in the United States during the sixties. Under this scenario, we find that the baseline equilibrium saving rate is $10 \%$ percent lower than in the sixties model economy. The result implies that if changes in marital risk are accompanied by changes in the distribution of earnings, the model falls short of predicting any decline in saving.

Table 5: Model Economy: Actual and Hypothetical Saving Rates. (Demographic and Earnings Change)

Expression Saving Rate

$\begin{array}{lllll}\text { Actual Saving Rate of the Eighties } & \sum_{j \in \mathcal{J}} \mu_{j}^{80}\left(\frac{y_{j}}{Y}\right)^{80} & \hat{s}_{j}^{80} & 1.00 \\ \text { Population Structure of the Sixties } & \sum_{j \in \mathcal{J}} \mu_{j}^{60}\left(\frac{y_{j}}{Y}\right)^{80} & \hat{s}_{j}^{80} & 1.83 \\ \text { Relative Incomes of the Sixties } & \sum_{j \in \mathcal{J}} \mu_{j}^{80}\left(\frac{y_{j}}{Y}\right)^{60} & \hat{s}_{j}^{80} & 0.90 \\ \text { Population Structure and Incomes of the Sixties } & \sum_{j \in \mathcal{J}} \mu_{j}^{60}\left(\frac{y_{j}}{Y}\right)^{60} & \hat{s}_{j}^{80} & 1.60 \\ \text { Actual Saving Rate of the Sixties } & \sum_{j \in \mathcal{J}} \mu_{j}^{60}\left(\frac{y_{j}}{Y}\right)^{60} & \hat{s}_{j}^{60} & 0.90\end{array}$

We now ask ourselves, why is the equilibrium saving rate in this model economy less than that found in the low marital risk model? The equilibrium effects of changes in relative earnings are twofold. One the one hand, saving in this model might be higher than in the low marital risk model, since the relative earnings of females are lower, the costs associated with marital dissolution are greater. On the other hand, the need to save for retirement might be less in this model (relative to the low marital risk model), since the importance of labor earnings of older age groups has fallen since the sixties. ${ }^{24}$ From our results, we infer the latter effect to dominate the former.

\footnotetext{
${ }^{24}$ The fall in old-age labor earnings can be attributed to a more generous social pension program.
} 


\section{B The Specific Properties of Divorce and Illegitimacy}

In previous sections, we study the equilibrium effect of demographic change that results from a combination of reduced divorce and illegitimacy. However, we are also interested in understanding the extent to which changes in divorce and illegitimacy, in isolation, work to affect aggregate saving. For that, we construct two model economies: one with the divorce patterns of the sixties and the other with the illegitimacy patterns of the sixties. Our results show that divorce and illegitimacy behave similarly, although the effects of changes in population structure due to changes in illegitimacy are slightly greater in magnitude. In addition, as Table 6 shows, the equilibrium saving rates of lower divorce on the one hand and lower illegitimacy on the other are each about $1 \%$ higher than the baseline saving rate. (Recall that the combined effect of lower divorce and illegitimacy gave us an equilibrium saving rate which was $2 \%$ greater than the baseline.) The evidence indicates that neither of these factors (in isolation) can contribute much to the fall in the U.S. saving rate.

Table 6: Model Economy: Actual and Hypothetical Saving Rates. (Isolating the Effect of Changes in Divorce and Illegitimacy)

\begin{tabular}{ccc} 
Expression & \multicolumn{2}{c}{ Saving Rate } \\
Divorce & Illegit.
\end{tabular}

\begin{tabular}{|c|c|c|c|}
\hline Actual Saving Rate of the Eighties & $\sum_{j \in \mathcal{J}} \mu_{j}^{80}\left(\frac{y_{j}}{Y}\right)^{80} \hat{s}_{j}^{80}$ & 1.00 & 1.00 \\
\hline Population Structure of the Sixties & $\sum_{j \in \mathcal{J}} \mu_{j}^{60}\left(\frac{y_{j}}{Y}\right)^{80} \hat{s}_{j}^{80}$ & 1.31 & 1.43 \\
\hline Relative Incomes of the Sixties & $\sum_{j \in \mathcal{J}} \mu_{j}^{80}\left(\frac{y_{j}}{Y}\right)^{60} \hat{s}_{j}^{80}$ & 0.94 & 0.93 \\
\hline Population Structure and Incomes of the Sixties & $\sum_{j \in \mathcal{J}} \mu_{j}^{60}\left(\frac{y_{j}}{Y}\right)^{60} \hat{s}_{j}^{80}$ & 1.23 & 1.32 \\
\hline Actual Saving Rate of the Sixties & $\sum_{j \in \mathcal{J}} \mu_{j}^{60}\left(\frac{y_{j}}{Y}\right)^{60} \quad \hat{s}_{j}^{60}$ & 1.01 & 1.01 \\
\hline
\end{tabular}

\section{Sensitivity Analysis}

To explore the robustness of our findings, we look at a variety of other versions of the model economies that differ on the most delicate features of our calibration: the size of the pecuniary costs associated with divorce and the relative weight assigned to each member of the couple. 


\section{A Divorce Under Costless Resources}

In this section, we are interested in understanding the extent to which the behavioral response associated with increases in the rate of marital dissolution is affected by changes in the cost of divorce. In our previous simulations, we assumed that when marriage ends through divorce, $40 \%$ of common assets are destroyed in the split. Now we assume that common assets are not destroyed and are split as follows: $\psi_{m}=0.4$ and $\psi_{f}=0.6$. The absence of transaction costs not only increases the expected return to saving for married couples, but also makes divorce less costly. The effect on household saving behavior is conflicting. While higher expected returns encourage married couples to save more because divorce is less costly, precautionary saving motives are less relevant.

Our results are similar to those described in the asset destruction case. We find that the equilibrium saving rate in the no-asset-destruction baseline model is $6.96 \%$, compared with $6.38 \%$ in the standard asset destruction baseline model. In addition, changes in the incidence of divorce and illegitimacy have virtually no effect on aggregate saving. As Table 7 indicates, the saving rate in the low marital risk model is only $0.7 \%$ higher than that found in the no asset destruction baseline model. (Recall that in the presence of asset destruction the low marital risk saving rate is $2 \%$ higher than the baseline.) Savings are normalized so that the saving rate of the eighties model economy (in the absence of asset destruction) is unity.

Table 7: Model Economy: Actual and Hypothetical Saving Rates. (The Case of Costless Divorce Under Demographic Change Only)

Expression

$\begin{array}{llll}\sum_{j \in \mathcal{J}} \mu_{j}^{80} & \left(\frac{y_{j}}{Y}\right)^{80} & \hat{s}_{j}^{80} & 1.00 \\ \sum_{j \in \mathcal{J}} \mu_{j}^{60}\left(\frac{y_{j}}{Y}\right)^{80} & \hat{s}_{j}^{80} & 1.94 \\ \sum_{j \in \mathcal{J}} \mu_{j}^{80}\left(\frac{y_{j}}{Y}\right)^{60} & \hat{s}_{j}^{80} & 0.88 \\ \sum_{j \in \mathcal{J}} \mu_{j}^{60} & \left(\frac{y_{j}}{Y}\right)^{60} & \hat{s}_{j}^{80} & 1.67 \\ \sum_{j \in \mathcal{J}} \mu_{j}^{60} & \left(\frac{y_{j}}{Y}\right)^{60} & \hat{s}_{j}^{60} & 1.01\end{array}$

Like in the asset destruction model, we find that while changes in the structure of 
households, the product of higher divorce and illegitimacy, work to reduce the rate of saving, changes in the saving behavior and the relative income of households offset most of the decrease.

\section{B Changes in the Relative Weights of Married Couples}

In this section, we study the robustness of our model to changes in the weights we assign to the female and male spouses. In our previous simulations, we assumed that the interests of the female spouse and the male spouse were given equal consideration. Here we construct a model economy where the female spouse has a higher say in the consumption and saving decisions of the married couple. We assume that for all ages $i$ of the female spouse and ages $j$ of the male spouse, $\xi_{i, f, j}=0.6$, while $\xi_{j, m, i}=0.4$. Since females outlive males, marry males who are older, and face greater financial loss from marital dissolution, females' desire to save is greater. When the interest of the female spouse is given higher consideration, we would expect not only saving to be higher in the standard baseline model, but also a greater behavioral reaction to changes in marital risk.

As predicted, we find that the saving rate in this model calibrated to the eighties is $6.43 \%$, slightly higher than the saving rate in the standard baseline model $(6.38 \%)$. The effects of changes in divorce and illegitimacy on saving are slightly higher than those described in our previous simulations, where the interest of each spouse in the decision making of the married couple is given equal consideration. (See Table 8.) When females have a higher say in the decision making of the couple, we find that the saving rate in the sixties to be $3 \%$ higher than in the eighties. Therefore, while giving females a higher weight in the decision making process of the couple improves our results in the direction of the data, the proposed demographic changes persistently fall short of accounting for much of the decline in the U.S. saving rate.

\section{Transition}

In the previous sections, we compared steady-state saving rates across different demographic scenarios and found that the recent demographic change, the product of increases in marital risk, has not played a significant role in determining the fall in the U.S. saving rate. We now study whether some reduction in saving can be associated to the fact that people 
Table 8: Model Economy: Actual and Hypothetical Saving Rates. (The Case of Higher Female Spouse Decision Weights)

Expression Saving Rate

$\begin{array}{llll}\text { Actual Saving Rate of the Eighties } & \sum_{j \in \mathcal{J}} \mu_{j}^{80}\left(\frac{y_{j}}{Y}\right)^{80} & \hat{s}_{j}^{80} & 1.00 \\ \text { Population Structure of the Sixties } & \sum_{j \in \mathcal{J}} \mu_{j}^{60}\left(\frac{y_{j}}{Y}\right)^{80} & \hat{s}_{j}^{80} & 1.85 \\ \text { Relative Incomes of the Sixties } & \sum_{j \in \mathcal{J}} \mu_{j}^{80}\left(\frac{y_{j}}{Y}\right)^{60} & \hat{s}_{j}^{80} & 0.87 \\ \text { Population Structure and Incomes of the Sixties } & \sum_{j \in \mathcal{J}} \mu_{j}^{60}\left(\frac{y_{j}}{Y}\right)^{60} & { }_{\hat{s}}^{80} & 1.58 \\ \text { Actual Saving Rate of the Sixties } & \sum_{j \in \mathcal{J}} \mu_{j}^{60}\left(\frac{y_{j}}{Y}\right)^{60} & { }_{\hat{s}}^{60} & 1.03\end{array}$

have been preempting these social changes. It could very well be that households during the sixties behaved according to the rules of divorce and illegitimacy of the eighties, in which case, their saving rate would be much higher than what the low marital risk model predicts.

We construct two transitions that differ in how we treat changes in relative earnings. In the first transition, we assume that the initial saving rate is given by the equilibrium of the low marital risk economy, where relative earnings are constant at the eighties level. The final saving rate corresponds to that of the baseline model. We then suppose that even before any demographic change takes place, agents modify their behavior, preempting an increase in the likelihood of divorce and illegitimacy. We then calculate the saving rate over the demographic transition, where agents behave according to the baseline model.

The second transition differs from the first in that the relative earnings distribution is assumed constant at the sixties level throughout the transition. The initial equilibrium saving rate corresponds to that of the model economy, which combines the marital risk and earnings patterns of the sixties. The final saving rate is the equilibrium result in an economy with the marital risk patterns of the eighties, yet the earnings distribution of the sixties. Like in the other transition, we then assume that before any demographic change takes place, agents modify their behavior, forecasting an increase in marital risk. Savings are then calculated over the demographic transition, where agents behave according to the marital risk regime of the eighties, yet the relative earnings of the sixties.

Table 9 describes the evolution of saving rates along the transition. We assume the 
initial steady state is dated at 1950 and that the demographic structures found in 1950 and 1960 are equal. The sharp difference in saving rates between these two dates is due solely to differences in saving behavior, which result from the fact that agents are forecasting an increase in marital risk and are responding to such a forecast. In both transition scenarios, saving rates increase between 1950 and 1960 and fall monotonically over time to levels below the initial steady state.

Table 9: Saving Rates Along the Transition

\begin{tabular}{ccc}
\hline Year & Scenario I & Scenario II \\
\hline 1950 & $6.52 \%$ & $5.72 \%$ \\
1960 & $11.67 \%$ & $10.99 \%$ \\
1965 & $9.03 \%$ & $9.03 \%$ \\
1970 & $8.61 \%$ & $7.87 \%$ \\
1975 & $7.85 \%$ & $7.11 \%$ \\
1980 & $7.34 \%$ & $6.60 \%$ \\
1985 & $6.99 \%$ & $6.26 \%$ \\
1990 & $6.76 \%$ & $6.03 \%$ \\
1995 & $6.60 \%$ & $5.87 \%$ \\
2000 & $6.50 \%$ & $5.77 \%$ \\
9999 & $6.38 \%$ & $5.66 \%$ \\
\hline
\end{tabular}

Next, we ask ourselves whether the results of our transition resemble the evolution of the U.S. saving rate dating back to the fifties. For this purpose we use data compiled by Gokhale, Kotlikoff, and Sabelhaus (1996), who track the U.S. household saving rate between 1950 and 1993. ${ }^{25}$ Table A5 in Appendix 3 shows U.S. saving rates by decade. Saving rates remained broadly stable between the fifties and sixties (increasing only slightly) and decreased monotonically thereafter. In contrast, our transition results predict a sharp increase in saving between the fifties and sixties, followed by a similar monotonic drop. The evidence rejects the hypothesis that household saving would increase between the fifties and sixties, preempting a rise in the likelihood of divorce and illegitimacy.

\footnotetext{
${ }^{25}$ In contrast to Córdoba (1996), who employs CEX to calculate household saving rates, Gokhale, Kotlikoff, and Sabelhaus (1996) use the National Income and Product Accounts.
} 


\section{Conclusion}

In this paper, we question whether there is any relationship between recent changes in the structure of households, the product of the sharp increase in likelihood of divorce and illegitimacy, and the decline in the rate of saving, observed in the United States between the sixties and eighties. To this purpose, we construct a general equilibrium, overlapping generations model that distinguishes between the sexes and in which agents are subject to exogenous uninsurable changes in their household type. Our findings indicate that the recent increase in marital risk can account for only a modest decline in saving. The explanation lies in that while we have observed a decline in the number of high-saving married households, the effect is offset by an increase in household saving resulting from increases in marital risk.

The framework and methodology developed in this paper should also allow us to address a broad range of policy issues. Johnson and Skinner (1986) find that the rise in the U.S. divorce rate between 1960 and 1980 can explain close to $20 \%$ of the observed increase in female labor force participation. Their results indicate that while actual separation marginally reduced market effort for males, it led to a substantial rise in women's working hours. In addition, and perhaps more interestingly, they find that females respond to a higher probability of divorce by working to gain more job experience. Their findings suggest that expanding preferences to include time allocation decisions would enrich the set of issues that could be studied in relation to marital risk.

There exists a broad range of income taxes and government welfare programs that are marital status-dependent and therefore affect intrahousehold saving and time allocation decisions. Take the case of social security, where today over one-quarter of all benefit payments are made to surviving spouses and dependents. Our two-sex framework provides us with an empirically consistent way of studying how public provision of retirement and life insurance might affect private saving, life insurance ownership, and welfare across household members. $^{26}$

Finally, our framework can be used to address issues in more traditional fields of

\footnotetext{
${ }^{26}$ Cubeddu (1995) finds that the U.S. social security system effectively transfers resources from males to females. However, he models the life-cycle behavior of single men and women and treats social security purely as a retirement insurance program. He regards this as a serious limitation and suggests incorporating survivor and spouse insurance in a modeling context where men and women make joint economic decisions.
} 
macroeconomics, such as business cycles. The data show huge differences in the time allocation patterns between market and home production activities of agents who differ according to sex and marital status. In addition, we find that women and young workers suffer larger employment volatilities than other demographic groups. Standard business cycle models assume workers are identical and, therefore, are incapable of predicting why different demographic groups observe different cyclical variations in their employment. These extensions can help us not only understand these empirical regularities, but also asses the impact of aggregate fluctuations on the welfare of different demographic groups. 


\section{References}

Auerbach, A. J. and Kotlikoff, L. J. 1987. Dynamic Fiscal Policy. Cambridge University Press, New York.

Auerbach, A. J. and Kotlikoff, L. J. 1992. The Impact of the Demographic Transition on Capital Formation. Scandinavian Journal of Economics, 94 (2), 282-295.

Auerbach, A. J., Kotlikoff, L. J., Hagemann, R. P., and Nicoletti, G. 1989. The Economic Dynamics of an Ageing Population: The Case of Four OECD Countries. OECD Economic Studies, 12, 97-130.

Bane, M. J. and Ellwood, D. T. 1986. Slipping into and out of Poverty: The Dynamics of Spells. Journal of Human Resources, 21, 1-23.

Becker, G. S. 1991. A Treatise on the Family. Harvard University Press, Cambridge, MA.

Browning, M. 1994. The Saving Behavior of a Two Person Household. Working Paper No. 94-06, McMaster University.

Browning, M., Bourguignon, F., Chiappori, P., and Lechene, V. 1994. Income and Outcomes: A Structural Model of Intrahousehold Allocation. Journal of Political Economy, 102(6), $1067-1096$.

Cherlin, A. 1992. Marriage, Divorce, Remarriage. Harvard University Press, Cambridge, MA.

Córdoba, J.-P. 1996. The Impact of Demographic Development and Household Structure on Personal Savings. Ph.D. thesis, University of Pennsylvania.

Cubeddu, L. M. 1995. The Role of Household Composition, Formation and Dissolution in Life Cycle Economies: Theory and Evidence. Ph.D. thesis, University of Pennsylvania.

DaVanzo, J. and Rahman, O. 1993. American Families: Trends and Correlates. Population Index, 59, 350-385.

Díaz-Gimenez, J., Quadrini, V., and Ríos-Rull, J.-V. 1997. Dimensions of Inequality: Facts on the U.S. Distribution of Earnings, Income and Wealth. Federal Reserve Bank of Minneapolis Quarterly Review, 21, 3-21.

Gokhale, J., Kotlikoff, L. J., and Sabelhaus, J. 1996. Understanding the Postwar Decline in U.S. Saving: A Cohort Analysis. NBER Working Paper No. 5571.

Hurd, M. D. 1989. Mortality Risk and Bequests. Econometrica, 57(4), 779-813.

Johnson, W. R. and Skinner, J. 1986. Labor Supply and Marital Separation. American Economic Review, 76, 455-469.

Kimball, M. S. 1990. Precautionary Saving in the Small and in the Large. Econometrica, 58, 53-73. 
Kotlikoff, L. J. and Spivak, A. 1981. The Family as an Incomplete Annuities Market. Journal of Political Economy, 89(2), 372-91.

Quadrini, V. and Ríos-Rull, J.-V. 1997. Understanding the U.S. Distribution of Wealth. Federal Reserve Bank of Minneapolis Quarterly Review, 21, 22-36.

Ringen, S. 1991. Households, Standard of Living and Inequality. Review of Income and Wealth, 37, 1-13.

Ríos-Rull, J.-V. 1994. Population Changes and Capital Accumulation: The Aging of the Baby Boom. Unpublished Manuscript, University of Pennsylvania.

Ríos-Rull, J.-V. 1996. Life Cycle Economies and Aggregate Fluctuations. Review of Economic Studies, 63(3)(215), 465-490. 


\section{Appendix 1. Computation of the Equilibrium}

Our model presents us with a series of technical difficulties that render standard algorithm solutions insufficient. Perhaps the most important problem is that the agent's problem cannot be solved backwards as in standard overlapping generations models. The standard procedure is to go to the last period of an agent's life, where the future is no longer relevant, and solve for the behavior of the agent. In turn, this behavior describes the nature of the future for agents of the previous age. The recursive nature of the problem allows us to determine the behavior of all agents. Consider now our two-sex environment. If agents are single in the last period of life, we can solve for their behavior. However, the problem of the married couple is more involved, since the future includes different possible evaluations by the two spouses. Suppose one spouse is in his or her last period of life, while the other is not. To determine the behavior of this married couple, we must know the behavior of the younger spouse. Since the younger spouse can potentially remarry, the behavior of all other agents in the economy has to be simultaneously determined in order to solve for his or her behavior.

The question now is how to translate the described difficulties into a solution algorithm. In order to solve for the behavior of the agent, we must simultaneously solve for the behavior of all agents. We must provide guesses not only for the decision rule of agents but also for the distribution of assets in the economy, since agents must take this into account when faced with the potential of marriage. The algorithm for computing an equilibria for this economy is as follows:

1. Provide initial values for relative factor prices.

2. Provide an initial guess for the economy's wealth distribution $\left\{\phi_{i, g, z}^{o}\right\}$ and decision rules $\left\{y_{i, g, z}^{o}\right\}$.

3. Given factor prices and the economy's wealth distribution and decision rules, we solve the dynamic programming problem for all agents and obtain new decision rules $\left\{y_{i, g, z}^{\prime}\right\}$.

4. If the new decision rules approximately equal our decision rules guess, we continue. Otherwise, we update our guess for the decision rules and return to step 3.

5. After decision rules converge, the associated new wealth distribution is determined: $\left\{\phi_{i, g, z}^{\prime}\right\}$. If the new wealth distribution approximately equals our wealth distribution guess, we are done. Otherwise, we adjust our guess, for the wealth distribution and return to step 3.

We approximate the true decision rules with piecewise linear functions. To solve the dynamic programming problem, we assign a uniform grid on the space of asset holdings. To reduce computation time, the grid on assets used to compute decision rules is much coarser than that used to compute the economy's wealth distribution. In addition, we define assets in per adult values, rather than in per household values. The number of grid points for decision rules is 41 , while the number of grid points on the economy's wealth distribution is 101 . Since 
we assume that agents are liquidity-constrained, we restrict the lower bound on the assets' values to be zero. We also make sure that the upper bound on assets is nonbinding.

\section{A 1. 1. Demographics Change versus Behavioral Change}

We are interested not only in comparing steady state equilibrium outcomes, but also in determining the extent to which our equilibrium results are the product of changes in the composition of households or changes in their saving behavior induced by changes in marital risk. In this subsection, we describe the implications for capital accumulation of isolating demographic change from behavioral change, as we move from a low marital risk economy to one where marital risk is greater. Variables associated with the low divorce and illegitimacy risk economy are labeled with superscript low, while high marital risk variables have superscript high. In what follows, we outline the steps involved.

1. Compute the steady state decision rules and the associated wealth distribution for the low marital risk economy following the procedure outlined in the previous section: $\left\{y_{i, g, z}^{l o w}\left(\phi^{l o w}, \pi^{l o w}\right)\right\}$ and $\left\{\phi_{i, g, z}^{\text {low }}\left(y^{\text {low }}, \pi^{\text {low }}, \mu^{\text {low }}\right)\right\}$, respectively.

2. Compute the stationary demographic structure associated with the high marital risk regime: $\mu_{i, g, z}^{h i g h}\left(\pi^{h i g h}\right)$.

3. Determine the capital stock implied by the demographic structure of the high marital risk economy. However, isolate these demographic changes from changes in decision rules implied by the increase in marital risk:

$$
K=\sum_{i, z} \mu_{i, f, z}^{\text {high }} \int_{a \in \mathcal{A}} a \phi_{i, f, z}^{\text {low }}(d a)+\sum_{i} \sum_{z \in s_{o}, s_{w}} \mu_{i, m, z}^{\text {high }} \int_{a \in \mathcal{A}} a \phi_{i, m, z}^{\text {low }}(d a) .
$$

Above, we describe the steps involved in determining the implications for economy aggregates of changes in the demographic structure of an economy when they are isolated from corresponding changes in the behavior of households. Likewise, we can determine the aggregate implications of changes in the behavior of households as we move from a low to a high marital risk regime, while abstracting from the implied population structure changes. The algorithm is outlined below.

1. Compute the steady state decision rules and the associated wealth distribution for the high marital risk economy, following the procedure outlined in the previous section: $\left\{y_{i, g, z}^{h i g h}\left(\phi^{h i g h}, \pi^{h i g h}\right)\right\}$ and $\left\{\phi_{i, g, z}^{h i g h}\left(y^{h i g h}, \pi^{h i g h}, \mu^{h i g h}\right)\right\}$, respectively.

2. Compute the stationary demographic structure associated with the low marital risk regime: $\mu_{i, g, z}^{\text {low }}\left(\pi^{\text {low }}\right)$.

3. Determine the capital stock implied by the decision rules of the high marital risk economy. However, isolate these behavioral changes from demographic changes implied by the increase in marital risk:

$$
K=\sum_{i, z} \mu_{i, f, z}^{l o w} \int_{a \in \mathcal{A}} a \phi_{i, f, z}^{\text {high }}(d a)+\sum_{i} \sum_{z \in s_{o}, s_{w}} \mu_{i, m, z}^{\text {low }} \int_{a \in \mathcal{A}} a \phi_{i, m, z}^{\text {high }}(d a) .
$$




\section{Appendix 2. Calculation of Individual Transition Probabilities}

1. We use the fact that transition from one spouse to another involves a spell of being single. We construct transitions from married to married distinguishing by age by using information on transitions from single to married. Specifically, we construct the following statistics:

$$
\pi_{i, g}^{*}(\ell \mid j)=q_{i, g}\left(\frac{\hat{\pi}_{i, g}\left(s_{o} \mid j\right)}{\hat{\pi}_{i, g}(S \mid j)} \frac{\hat{\pi}_{i, g}\left(\ell \mid s_{o}\right)}{\hat{\pi}_{i, g}\left(M \mid s_{o}\right)}+\frac{\hat{\pi}_{i, g}\left(s_{w} \mid j\right)}{\hat{\pi}_{i, g}(S \mid j)} \frac{\hat{\pi}_{i, g}\left(\ell \mid s_{w}\right)}{\hat{\pi}_{i, g}\left(M \mid s_{w}\right)}\right)
$$

for $\ell=j+1$, and then add the probability of not remarrying:

$$
\pi_{i, g}^{*}(k \mid j)=\pi_{i, g}^{*}(k \mid j)+\left(1-q_{i, g}\right) \hat{\pi}_{i, g}(M \mid j)
$$

2. We have to account for mortality, and the PSID do not allow us to do so, since we cannot disentangle those who died from those who left the sample in 1985 compared to 1980. To properly account for mortality, we use the following steps: ${ }^{27}$

(a) We compute the complement of those who stay married to the same spouse, $\hat{x}_{i, g}(j)$ :

$$
\hat{x}_{i, g}(j)=1-\left(1-q_{i, g}\right) \pi_{i, g}^{*}(j+1 \mid j) .
$$

(b) We define the probability of marital dissolution as the maximum value of $\hat{x}_{i, g}(j)$ and the probability of spousal death:

$$
x_{i, g}(j)=\max \left\{\hat{x}_{i, g}(j),\left(1-\gamma_{j, g^{*}}\right)\right\} .
$$

(c) Then we redefine the transition probabilities and account for the agent's own probability of death as follows:

$$
\frac{\pi_{i, g}(z \mid j)}{\gamma_{i, g}}= \begin{cases}\frac{\hat{\pi}_{i, g}(z \mid j)}{\hat{x}_{i, g}(j)} x_{i, g}(j) & \text { for } z \in S \\ \frac{\pi_{i, g}^{*}(z \mid j)}{\hat{x}_{i, g}(j)} x_{i, g}(j) & \text { for } z \in M \text { and } z \neq j+1 \\ \left(1-x_{i, g}(j)\right)+q_{i, g} \frac{\pi_{i, g}^{*}(z \mid j)}{\hat{x}_{i, g}(j)} x_{i, g}(j) & \text { for } z \in M \text { and } z=j+1\end{cases}
$$

3. We make the transitions of males and females consistent with each other. (Recall that $\mu_{i, m, j}=\mu_{j, f, i}$ for all $i, j \in \mathcal{I}$.) We impose that the male's transition has to adjust to match the number of females of each type. We do this by scaling the rows of $\pi_{i, m, j}$ appropriately while conserving the ratios generated by the original matrix between single males with and without dependents, and between the transition from and to marriage across the different age groups of the wives. ${ }^{28}$

\footnotetext{
${ }^{27}$ While studies reveal that the probability of remarriage, controlling for age and sex, is slightly higher after divorce than after the death of a spouse, we assume that they are equal. See Cherlin (1992).

${ }^{28}$ The transformation also requires that the new matrix is a Markov matrix; that is, that no element is either negative or above 1 . This requires some additional rules when this property is violated. The description
} 


\section{Appendix 3. Tables and Figures of Interest}

Table A1: Transitional Probabilities for Males Between Marital Statuses

\begin{tabular}{ccccccc}
\hline & \multicolumn{3}{c}{ Conditional on Being Married } & \multicolumn{3}{c}{ Conditional on Being Single } \\
\hline Age & Married & Single w/o & Single w/ & Married & Single w/o & Single w/ \\
\hline $15-19$ & .800 & .200 & .000 & .169 & .804 & .027 \\
$20-24$ & .831 & .119 & .050 & .354 & .606 & .040 \\
$25-29$ & .885 & .079 & .036 & .387 & .573 & .040 \\
$30-34$ & .932 & .039 & .029 & .368 & .611 & .021 \\
$35-39$ & .931 & .041 & .028 & .163 & .698 & .140 \\
$40-44$ & .919 & .038 & .043 & .258 & .645 & .097 \\
$45-49$ & .941 & .036 & .024 & .273 & .636 & .091 \\
$50-54$ & .954 & .031 & .015 & .227 & .727 & .045 \\
$55-59$ & .928 & .063 & .009 & .125 & .833 & .042 \\
$60-64$ & .914 & .067 & .018 & .143 & .786 & .071 \\
$65-69$ & .930 & .039 & .031 & & & \\
$70-74$ & .882 & .105 & .013 & $.000^{*}$ & $.875^{*}$ & $.125^{*}$ \\
$75-80$ & .800 & .181 & .019 & & & \\
\hline
\end{tabular}

Table A2: Transitional Probabilities for Females Between Marital Statuses

\begin{tabular}{ccccccc}
\hline & \multicolumn{3}{c}{ Conditional on Being Married } & \multicolumn{3}{c}{ Conditional on Being Single } \\
\hline Age & Married & Single w/o & Single w/ & Married & Single w/o & Single w/ \\
\hline $15-19$ & .733 & .067 & .200 & .271 & .532 & .197 \\
$20-24$ & .847 & .039 & .114 & .366 & .454 & .180 \\
$25-29$ & .878 & .035 & .086 & .295 & .545 & .160 \\
$30-34$ & .895 & .023 & .082 & .179 & .696 & .125 \\
$35-39$ & .907 & .019 & .074 & .121 & .697 & .182 \\
$40-44$ & .898 & .024 & .079 & .123 & .690 & .187 \\
$45-49$ & .895 & .036 & .069 & .101 & .765 & .134 \\
$50-54$ & .898 & .039 & .062 & .073 & .818 & .109 \\
$55-59$ & .846 & .103 & .051 & .016 & .902 & .082 \\
$60-64$ & .850 & .121 & .029 & .013 & .948 & .039 \\
$65-69$ & .813 & .131 & .056 & & & $.037^{*}$ \\
$70-74$ & .724 & .241 & .034 & $.009^{*}$ & $.953^{*}$ & \\
$75-80$ & .681 & .203 & .116 & & & \\
\hline
\end{tabular}

Source: PSID 1980:1985.

* Averages of 65 to 80 .

of these rules is tedious and is available upon request. The rules are designed so that the new male transition matrix inherits as many properties as possible from the original. 
Table A3: Household Equivalence Scales

\begin{tabular}{lc}
\hline Marital Status & $\eta_{z}$ \\
\hline Single w/o Dependents & 1.000 \\
Single w/ Dependents & 1.750 \\
Female Spouse 15-19 & 2.200 \\
Female Spouse 20-24 & 2.325 \\
Female Spouse 25-29 & 2.450 \\
Female Spouse 30-34 & 2.575 \\
Female Spouse 35-39 & 2.700 \\
Female Spouse 40-44 & 2.450 \\
Female Spouse 45-49 & 2.200 \\
Female Spouse 50-54 & 1.950 \\
Female Spouse 55+ & 1.700 \\
\hline
\end{tabular}

Table A4: Actual and Hypothetical Saving Rates Across Model Economies

\begin{tabular}{|c|c|c|c|c|c|}
\hline & Divorce & Illegitimacy & $\begin{array}{c}\text { Divorce } \\
\text { Illegitimacy }\end{array}$ & $\begin{array}{c}\text { Divorce } \\
\text { Illegitimacy } \\
\text { Earnings } \\
\end{array}$ & Data \\
\hline$\sum_{j \in \mathcal{J}} \mu_{j}^{80}\left(\frac{y_{j}}{Y}\right)^{80} \hat{s}_{j}^{80}$ & 1.00 & 1.00 & 1.00 & 1.00 & 1.00 \\
\hline$\sum_{j \in \mathcal{J}} \mu_{j}^{60} \quad\left(\frac{y_{j}}{Y}\right)^{80} \hat{s}_{j}^{80}$ & 1.31 & 1.43 & 1.83 & 1.83 & 1.55 \\
\hline$\sum_{j \in \mathcal{J}} \mu_{j}^{80}\left(\frac{y_{j}}{Y}\right)^{60} \hat{s}_{j}^{80}$ & 0.94 & 0.93 & 0.87 & 0.90 & 0.87 \\
\hline$\sum_{j \in \mathcal{J}} \mu_{j}^{80}\left(\frac{y_{j}}{Y}\right)^{80} \hat{s}_{j}^{60}$ & 0.74 & 0.61 & 0.09 & -0.20 & 1.94 \\
\hline$\sum_{j \in \mathcal{J}} \mu_{j}^{60}\left(\frac{y_{j}}{Y}\right)^{60} \hat{s}_{j}^{80}$ & 1.23 & 1.32 & 1.56 & 1.69 & 1.38 \\
\hline$\sum_{j \in \mathcal{J}} \mu_{j}^{60}\left(\frac{y_{j}}{Y}\right)^{80} \hat{s}_{j}^{60}$ & 1.08 & 1.08 & 1.02 & 1.02 & 2.40 \\
\hline$\sum_{j \in \mathcal{J}} \mu_{j}^{80}\left(\frac{y_{j}}{Y}\right)^{60} \quad \hat{s}_{j}^{60}$ & 0.70 & 0.59 & 0.14 & -0.00 & 1.74 \\
\hline$\sum_{j \in \mathcal{J}} \mu_{j}^{60}\left(\frac{y_{j}}{Y}\right)^{60} \hat{s}_{j}^{60}$ & 1.01 & 1.01 & 1.02 & 0.90 & 2.15 \\
\hline
\end{tabular}

Table A5: U.S. Saving Rates: 1950-1993

\begin{tabular}{lc}
\hline Years & Saving Rate \\
\hline $1950-59$ & $11.5 \%$ \\
$1960-69$ & $11.7 \%$ \\
$1970-79$ & $10.8 \%$ \\
$1980-89$ & $5.9 \%$ \\
$1990-93$ & $3.2 \%$ \\
\hline
\end{tabular}

Source: Gokhale, Kotlikoff, and Sabelhaus (1996). 

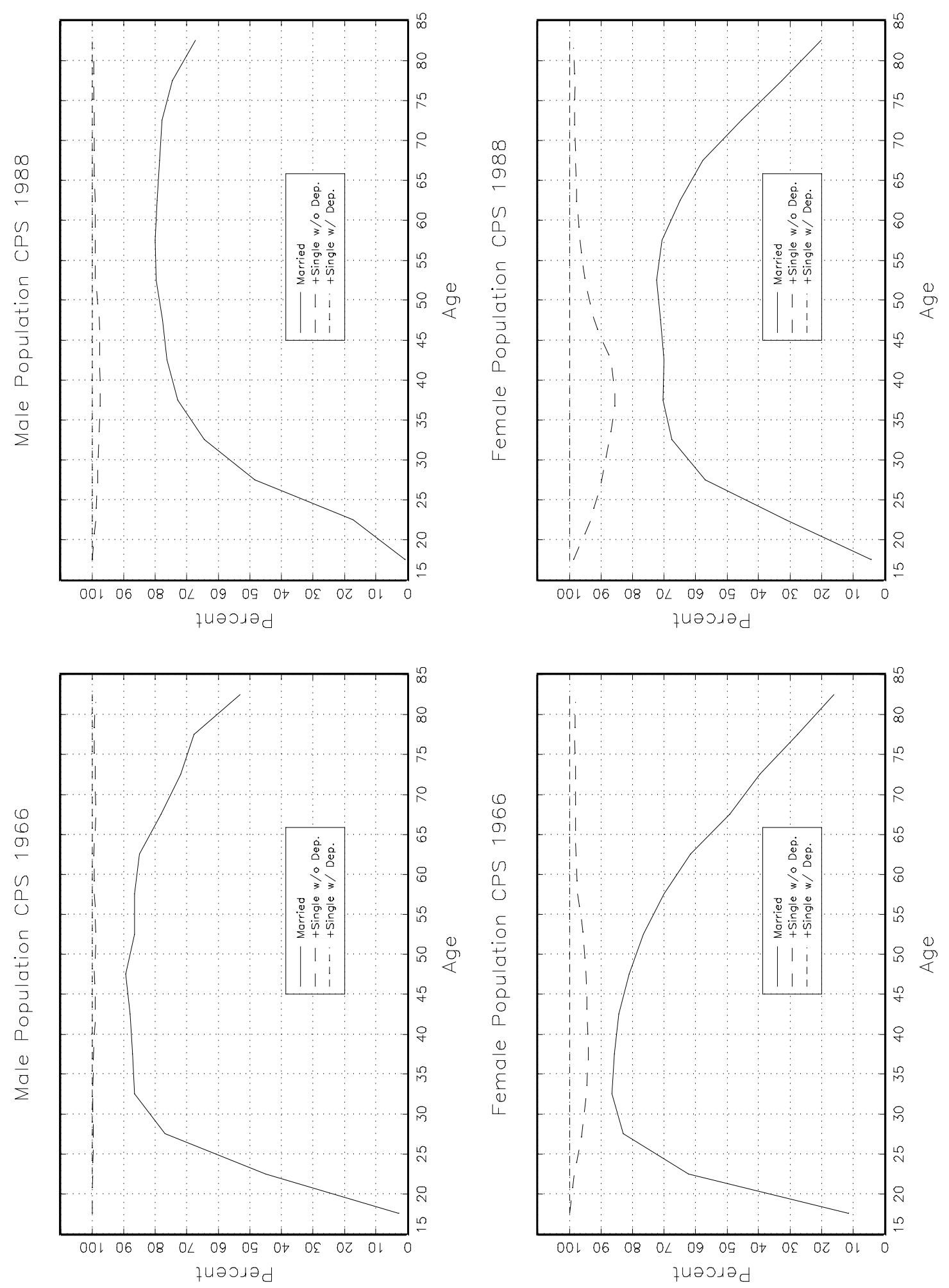

Figure 1: Demographic Structure by Sex and Marital Status: CPS 1988 and 1966 


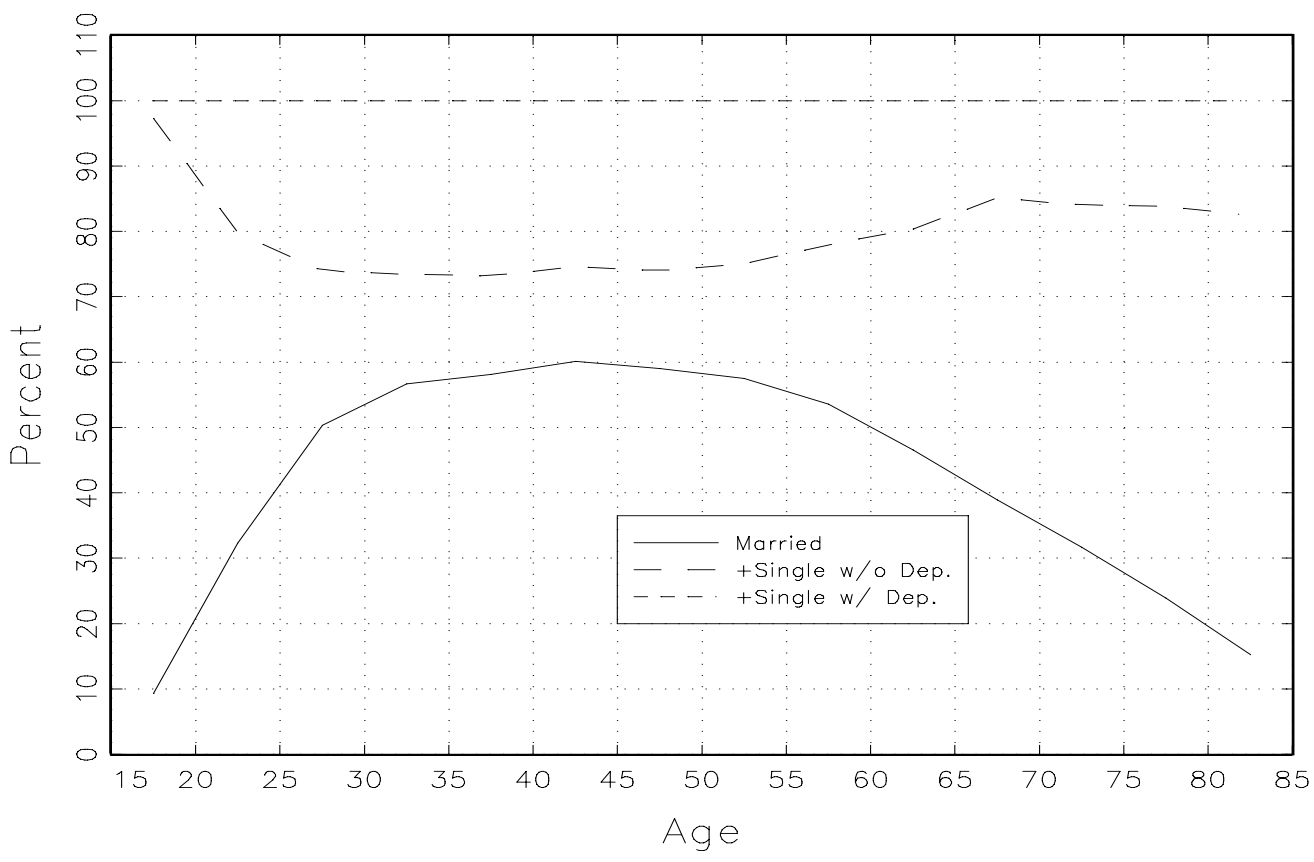

Figure 2: Baseline Demographic Structure by Marital Status (Eighties): Females 


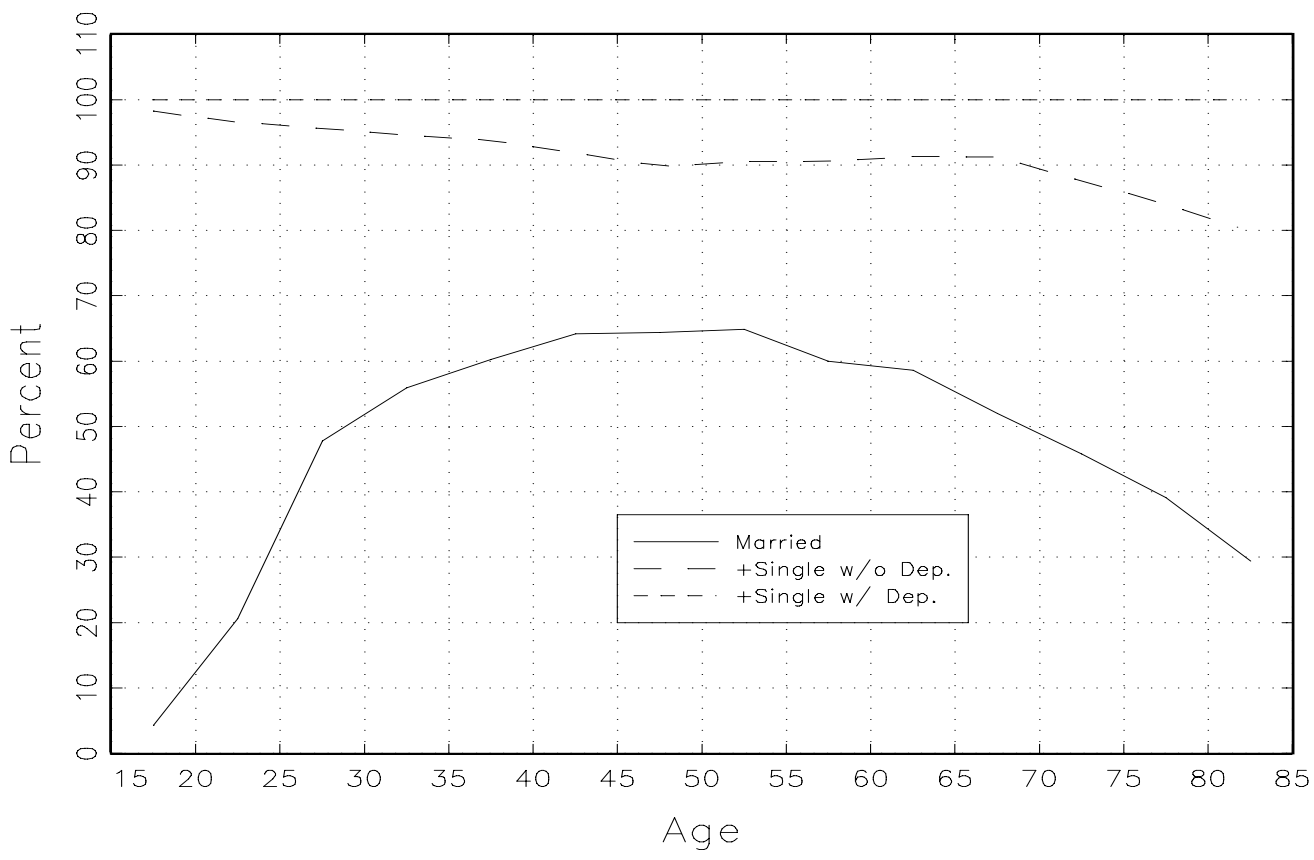

Figure 3: Baseline Demographic Structure by Marital Status (Eighties): Males 

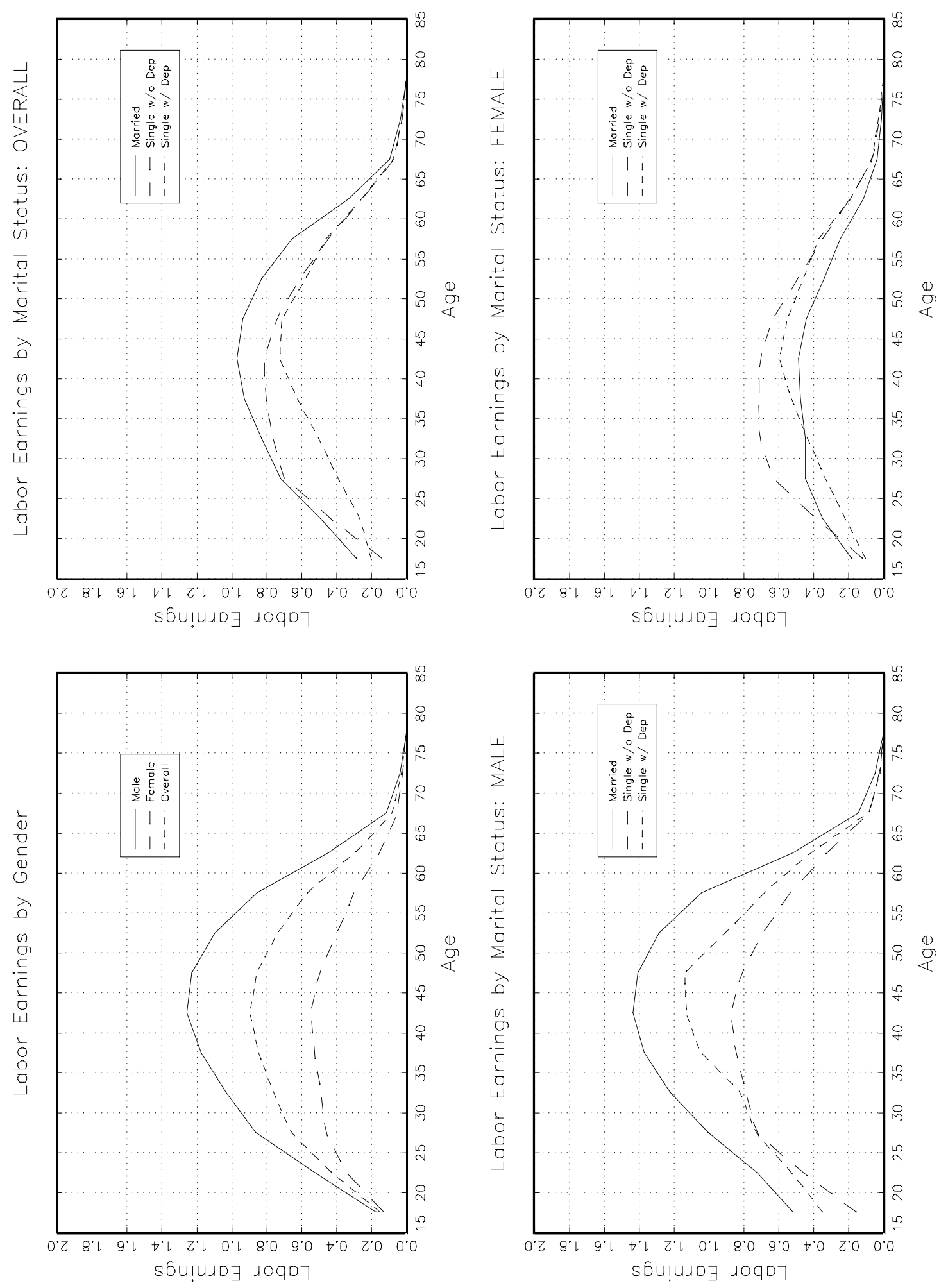

Figure 4: Earnings Index by Age, Sex, and Marital Status: CPS 1988 


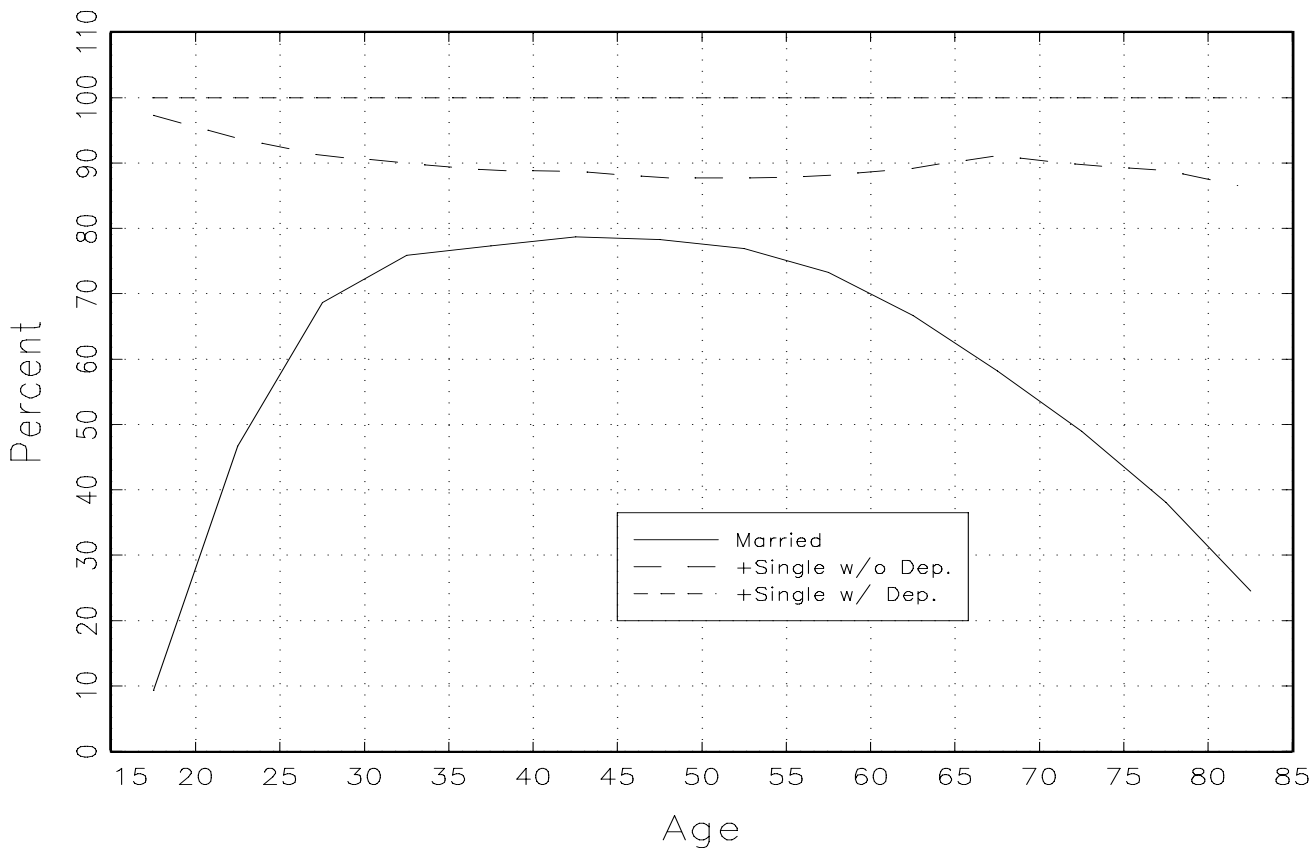

Figure 5: Low Marital Risk Demographic Structure by Marital Status (Sixties): Females 


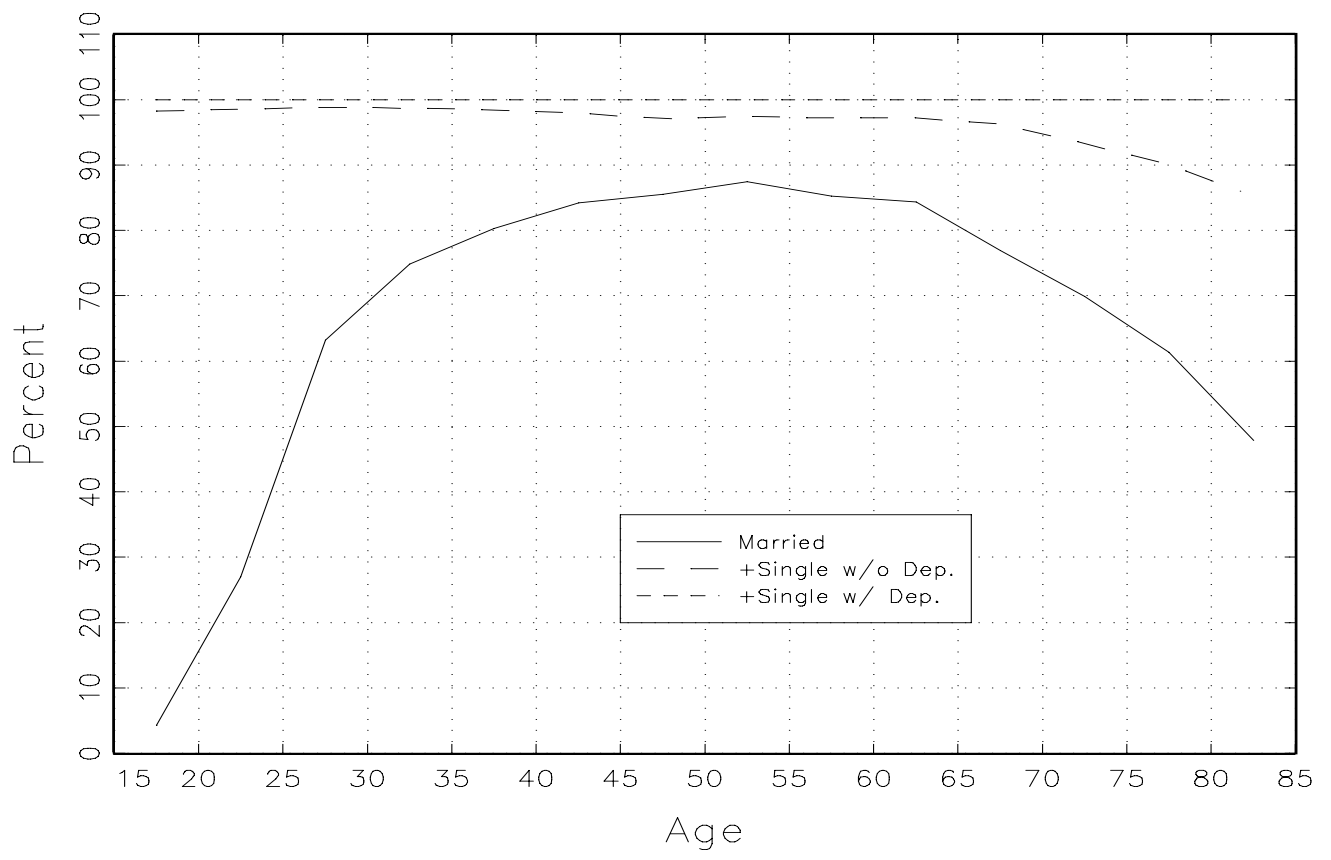

Figure 6: Low Marital Risk Demographic Structure by Marital Status (Sixties): Males 

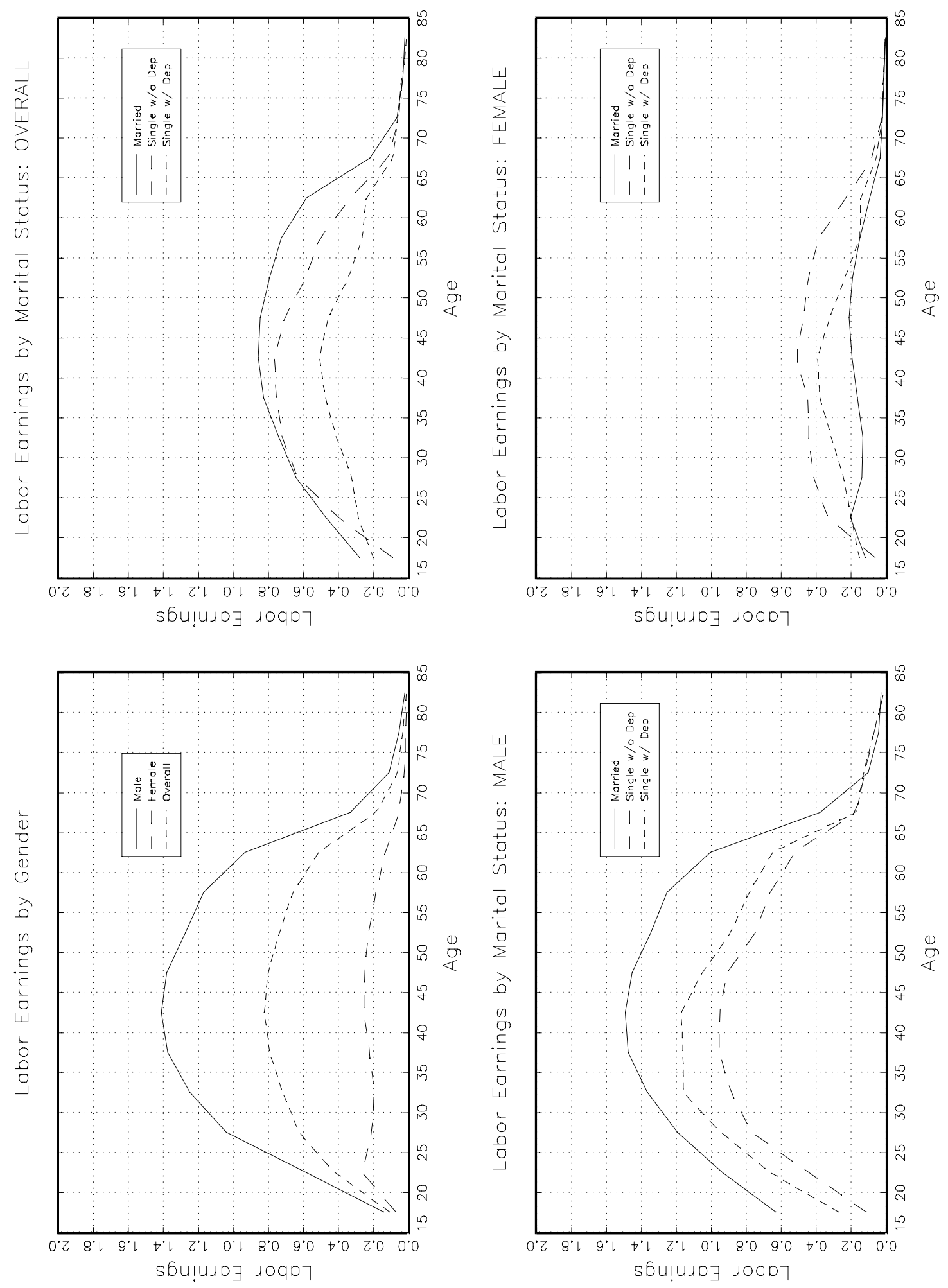

Figure 7: Earnings Index by Age, Sex, and Marital Status: CPS 1966 


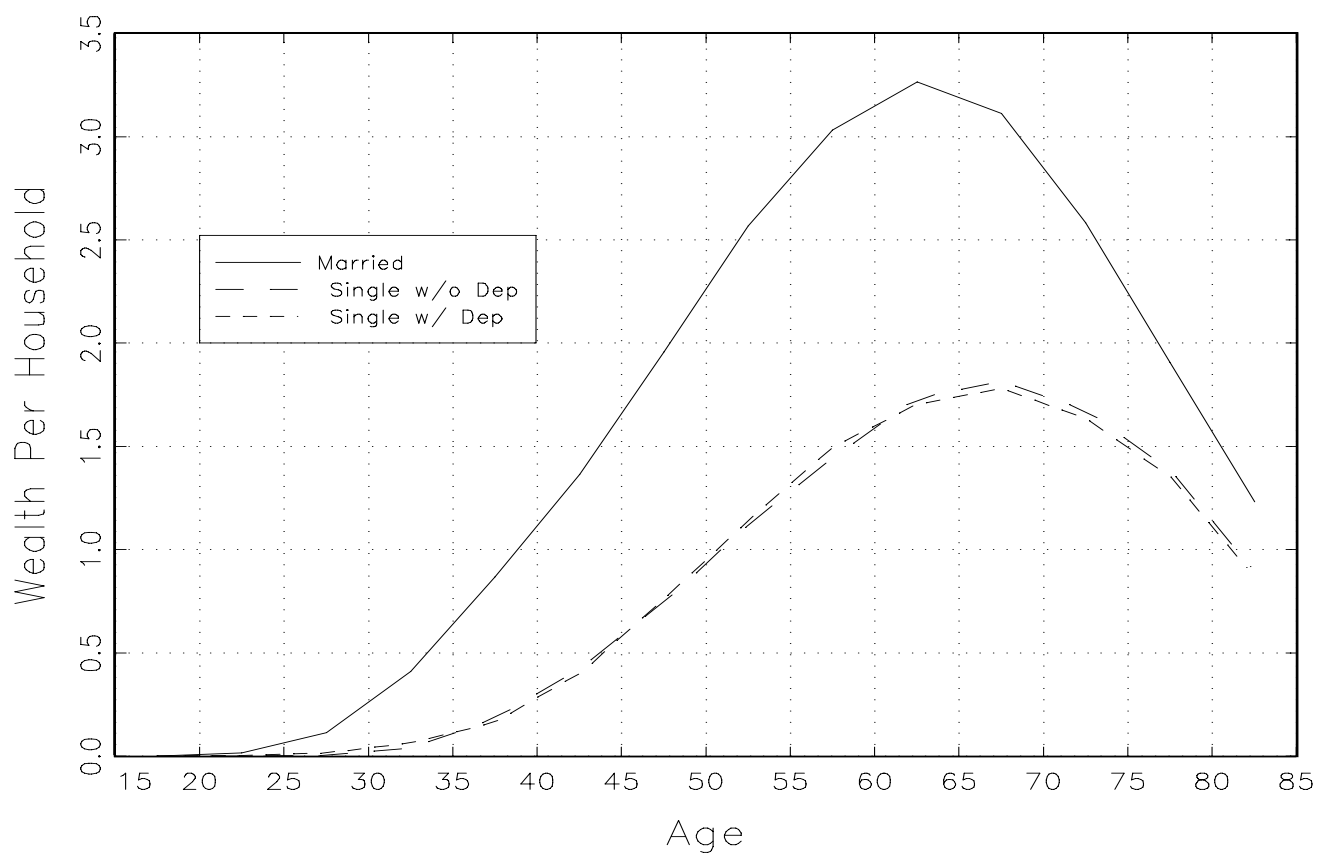

Figure 8: Average Wealth-Age Profile by Household Type: Baseline Economy 
Household Wealth

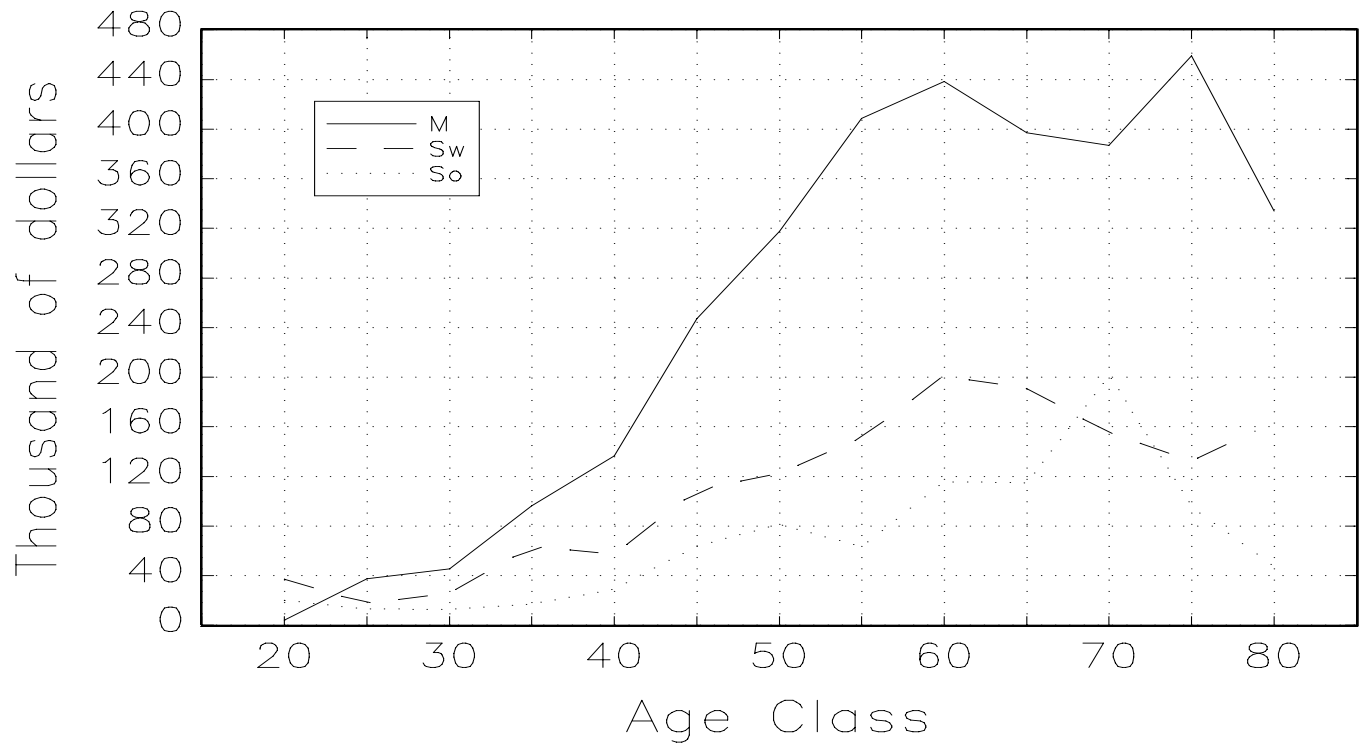

Figure 9: Average Wealth-Age Profile by Household Type Source: 1992 Survey of Consumer Finances 